Universidad de Lima

Facultad de Comunicación

Carrera de Comunicación

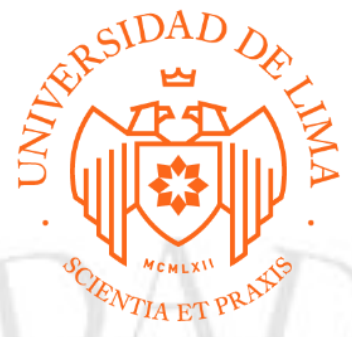

\title{
CAMPAÑA DE COMUNICACIÓN
}

INTEGRAL: CONDOMINIO VILLA DEL

\section{ATLETA}

Trabajo de Suficiencia Profesional para optar el Título Profesional de Licenciado en

Comunicación

Miguel Helguero Meza

Código 20101592

$$
\text { Lima - Perú }
$$

Setiembre de 2019 


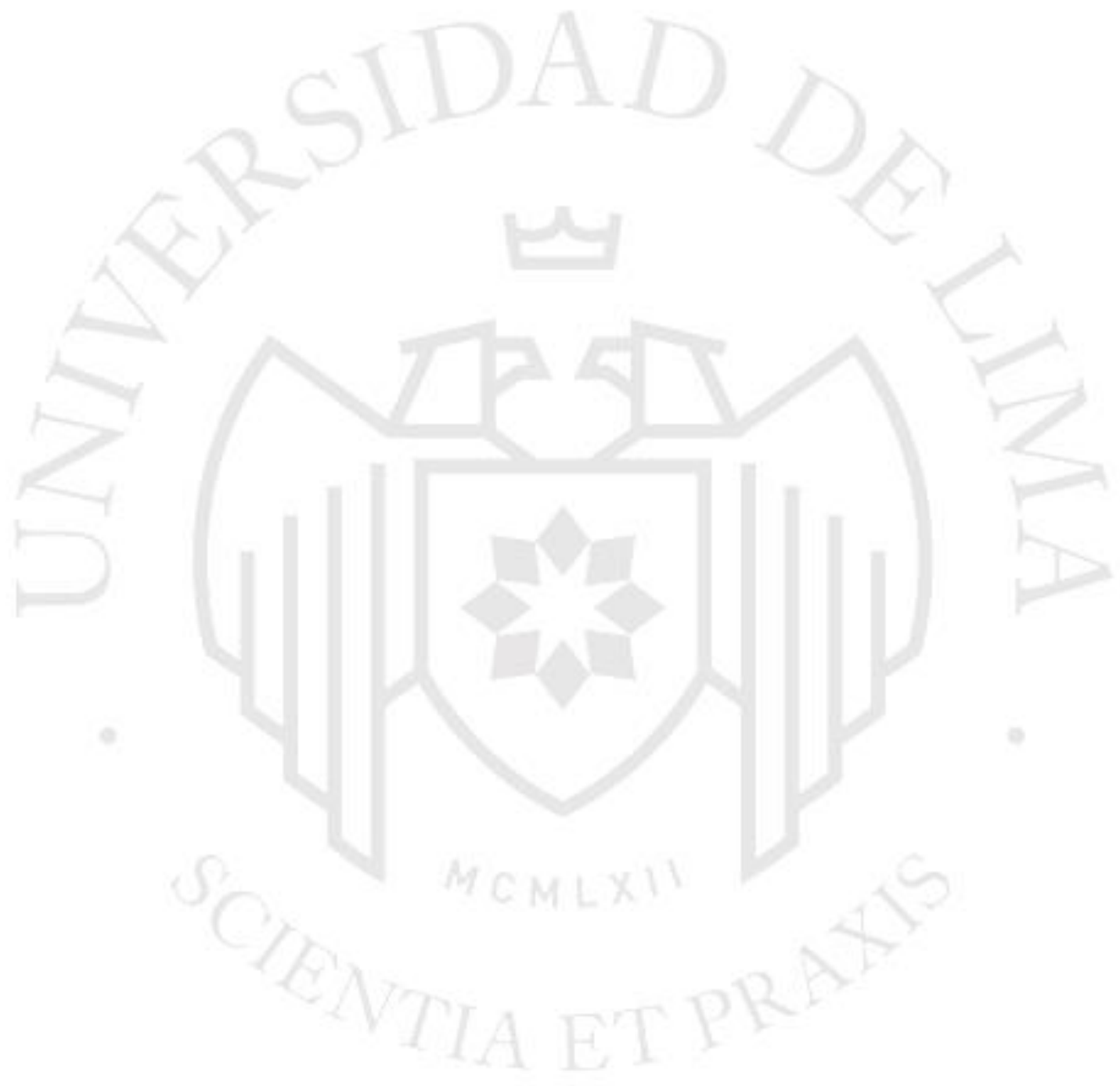




\section{CAMPAÑA DE COMUNICACIÓN INTEGRAL: CONDOMINIO VILLA DEL ATLETA}


Dirección web de las piezas y producciones de comunicación parte del trabajo

https://drive.google.com/drivelfolders/1xmmYeJAbel3fYHfOgckQ ALt2JrlUoc- $y$ ? usp $=$ sharing 


\section{RESUMEN EN ESPAÑOL}

El presente trabajo tiene como objetivo el desarrollo de la campaña integral de comunicación para el Condominio Villa del Atleta. Este proyecto fue construido con ocasión de los Juegos Panamericanos Lima 2019 y la venta de los departamentos se proyecta para Enero del 2020. Se desarrolló la identidad corporativa y un plan de marketing orientado a obtener los objetivos comerciales dispuestos: la venta del 100\% de los departamentos máximo hasta el segundo trimestre del año 2020.

Palabras clave: Juegos Panamericanos - Villa Panamericana - Plan de Marketing - Plan de Comunicación - Villa del Atleta

\section{RESUMEN EN INGLÉS}

The present document has as objective the development of the integral communication campaign for the Villa del Atleta Condominium. This project was built for the occasion of the Lima 2019 Pan American Games and the sale of the apartments is projected for January 2020. The corporate identity and a marketing plan were developed to obtain the commercial objectives set: the sale of $100 \%$ of the Maximum departments until the second quarter of the year 2020.

Keywords: Pan American Games - Villa Panamericana - Marketing Plan - Communication Plan - Villa del Atleta 


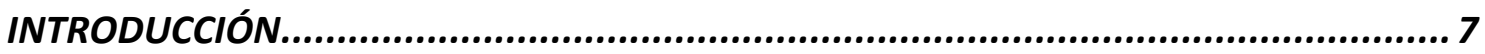

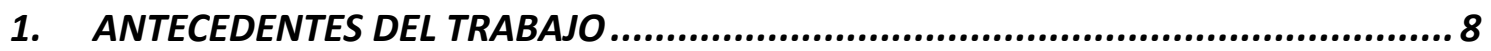

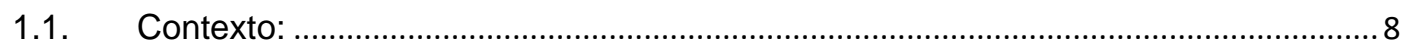

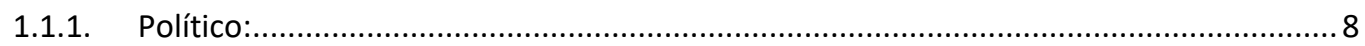

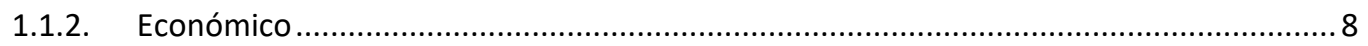

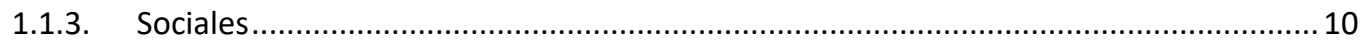

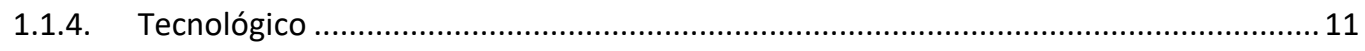

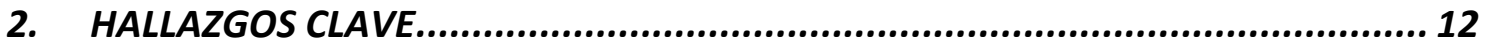

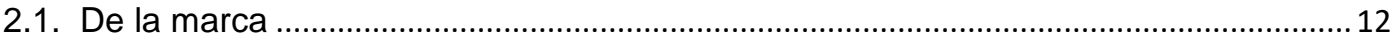

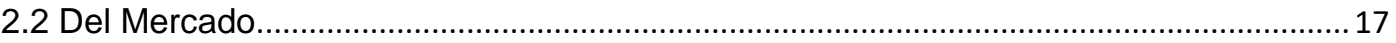

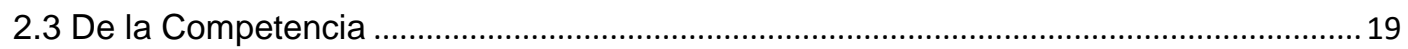

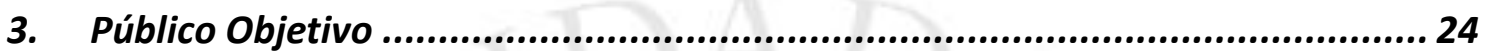

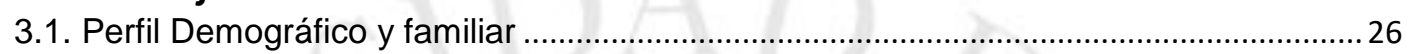

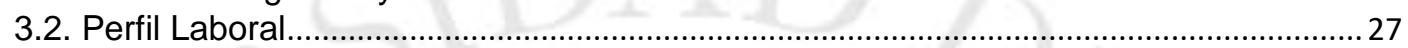

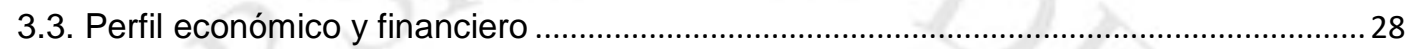

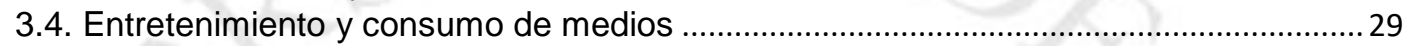

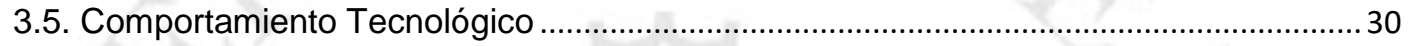

3.6. Información de personas con discapacidad física ............................................................. 31

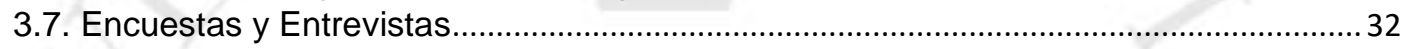

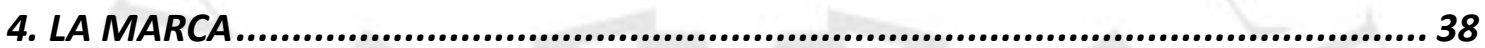

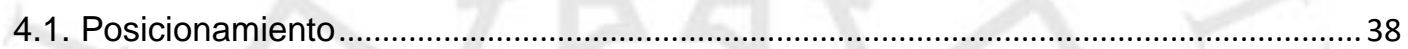

4.2. Promesa

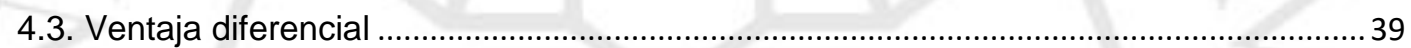

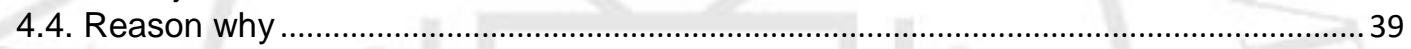

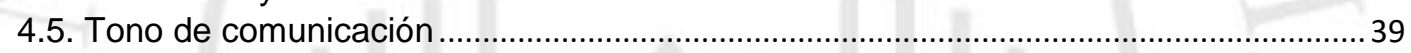

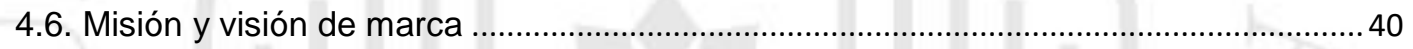

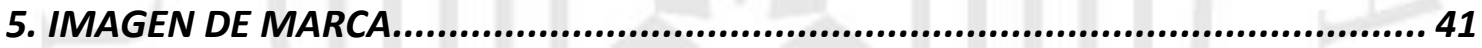

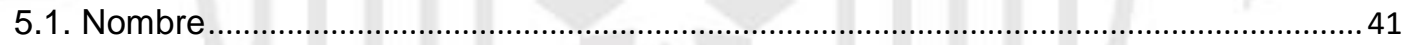

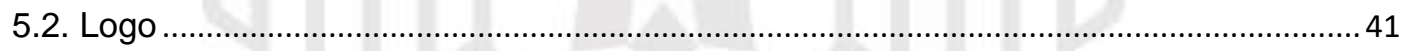

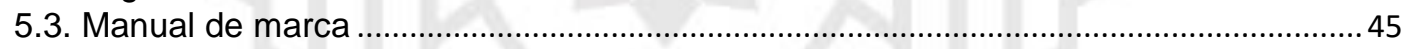

6. LA CAMPAÑA

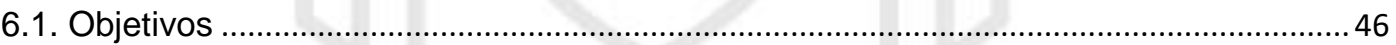

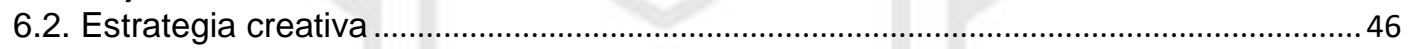

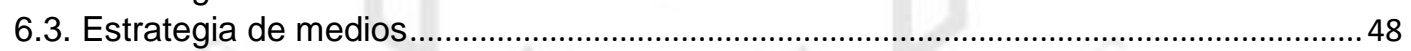

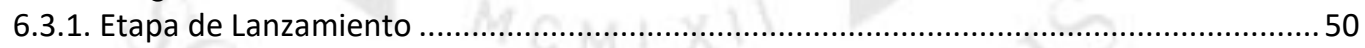

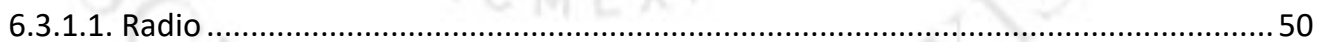

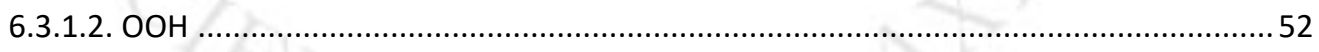

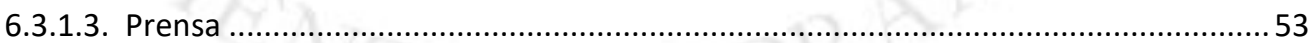

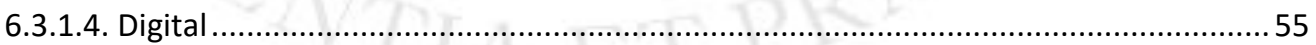

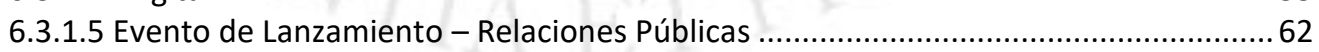

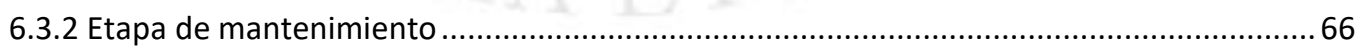

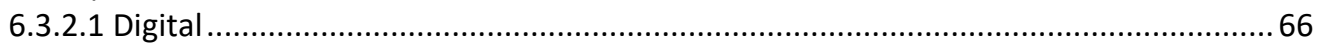

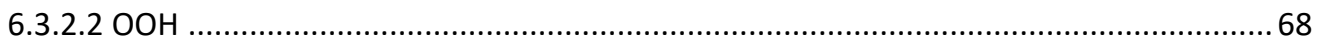

7. DISTRIBUCIÓN DE LA INVERSIÓN DE CAMPAÑA Y JUSTIFICACIÓN......................69

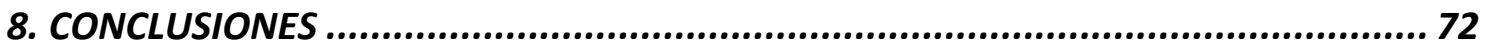

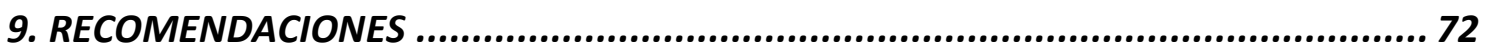

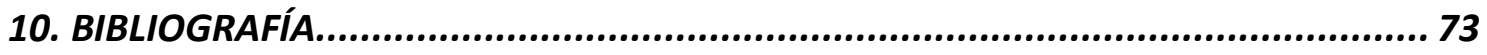

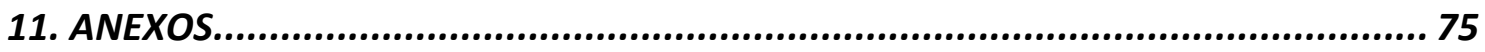




\section{INTRODUCCIÓN}

La Villa Panamericana es un condominio construido con motivo de los Juegos Panamericanos Lima 2019 realizados en el Perú. La construcción fue realizada por el convenio

de empresas Besco-Besalco, en el distrito de Villa El

Salvador. Consta de 1096 departamentos cuya construcción está avalada por estándares internacionales y son eco-amigables.

El objetivo comercial es lograr la venta del $100 \%$ de los departamentos en un periodo máximo al segundo trimestre del año 2020, para lo cual se ha desarrollado la identidad corporativa y un plan de marketing.

La identidad corporativa se realizó usando elementos alusivos al deporte, pero que también denoten que se trata de un proyecto inmobiliario. Se usaron colores que puedan lograr cercanía y transmitan la personalidad del producto.

El plan de marketing analizó la situación actual del mercado para lograr una estrategia adecuada. Se creó el concepto creativo "Vive como un campeón" que se comunicará a través de un mix de medios que se construyó de forma costo eficiente para lograr los objetivos comerciales. 


\section{ANTECEDENTES DEL TRABAJO}

\subsection{Contexto:}

Para poder entender el contexto actual que influye a la hora de crear una campaña en búsqueda de la venta de inmuebles, realizaremos un análisis PEST. Con esta herramienta tendremos un panorama más claro del mercado, junto con las oportunidades disponibles y retos a afrontar.

\subsubsection{Político:}

En cuanto al contexto político, la que influye directamente en la venta y compra de inmuebles es la Ley N\# 30730, que modificó artículos de la Ley de Bancarización. Entró en vigencia desde el 21 de agosto de 2018.

"A partir de la fecha, toda compra de vivienda y vehículos que supere las 3 unidades impositivas tributarias (UIT) deberá ser pagada obligatoriamente por medio del sistema bancario al entrar en vigencia la Ley № 30730, que impone la bancarización como medio para evitar la evasión fiscal, el lavado de activos y la corrupción." (El Peruano, 2018)

Tal como indica la SUNAT, toda operación que supere las 3 UIT (para el año 2019, 1 UIT tiene el valor de s/. 4,200, por lo que 3 UIT son s/. 12,000) tendrán que estar sujetas a una bancarización obligatoria. Con todo esto se llega a tener mayor control de las operaciones de riesgo, y esto conlleva a una compra y venta transparente de viviendas como es el caso que realizaremos.

\subsubsection{Económico}

Mediante el Informe de Actualización de Proyecciones Macroeconómicas 2019 - 2022, elaborado el 25 de abril de 2019 por el Ministerio de Economía y Finanzas (MEF), nos indican que para este año se tienen perspectivas favorables para el sector inmobiliario. Todo ello a causa del dinamismo en la venta de viviendas por parte del segmento de 
Fondo Mivivienda (sumado a sus Bonos otorgados y bajos costos de financiamiento). A esto, hay que sumarle el crecimiento de los créditos hipotecarios que se están dando, los cuales seguirán reduciéndose a niveles nunca antes vistos para la economía peruana.

"Por un lado, la venta de viviendas en Lima Metropolitana creció 12,6\% en 2018 y de acuerdo a Apoyo Consultoría esta se incrementaría 8,0\% en 2019. Así, en 2019, se venderían 17 mil unidades de viviendas (2018: 15 mil), la mayor cantidad desde 2014. Estas mayores ventas serían impulsadas por el aumento de las colocaciones de viviendas sociales del Fondo Mivivienda, y según proyecciones de esta institución, pasarían de 9 mil unidades en 2018 a 11 mil en 2019, la mayor cantidad de colocaciones desde 2013. En particular, destaca el incentivo del Bono Mivivienda Sostenible (BMS) o bono verde, el cual otorga un financiamiento entre $3 \%$ y $4 \%$ del valor de la vivienda siempre que cumpla con características de sostenibilidad. (Ministerio de Economía y Finanzas, 2019)
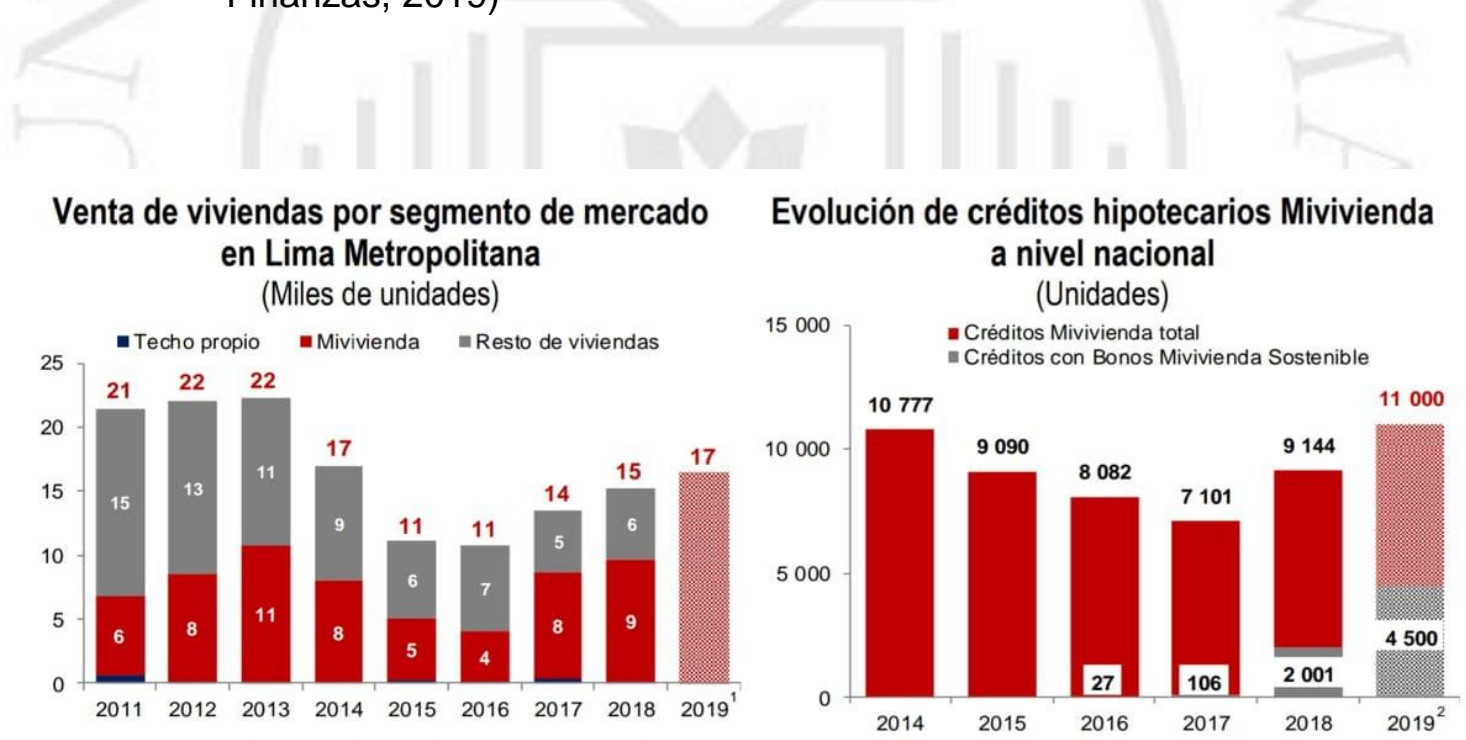

1/ Provección de Apovo Consultoria. 2/ Provección del Fondo Mivivienda.

Figura 1. Informe De Actualización De Proyecciones Macroeconómicas 2019-2022. Fuente: Ministerio de Economía y Finanzas

La información recolectada ayudará bastante a la hora de prospectar las ventas de los departamentos del Condominio Villa del Atleta, y aún más porque serán vendidos a través del Nuevo Crédito Mivivienda. 


\subsubsection{Sociales}

El sector inmobiliario peruano en los últimos años ha logrado un resurgimiento y actualmente proyecta una tendencia de ventas en ascenso. La preferencia del ciudadano, y al mismo tiempo del sector inmobiliario, es en la construcción y venta de departamentos.

Antonio Espinosa, Gerente General de inmobiliaria Desarrolladora, resume en las siguientes palabras el porqué del interés en aumentar el número de departamentos en venta en Lima:

"Lima no tiene hacia donde crecer, solo hacia arriba por eso el mercado apunta casi de manera unánime a un lugar (...) La preferencia es de departamentos de 3 habitaciones por temas familiares; sin embargo, hoy vemos compradores de 2 o hasta 1 dormitorio. Diría que el $14 \%$ de los compradores busca de un solo dormitorio." (GESTIÓN, 2017)

Según Abril Grupo Inmobiliario, en Lima la oferta inmobiliaria tiene una concentración en departamentos del 71\% (Año 2019). Además de los Fondos y créditos hipotecarios que favorecen el querer adquirir un departamento. El portal web Bolsalnmobiliaria.pe nos indica las siguientes ventajas por la que los compradores optan por ello:

- "Suelen contar con una mayor seguridad

- Los costos de mantenimiento son más bajos que los de una casa pues suelen pagarse por áreas comunes

- El precio de un departamento suele ser más bajo que el de una casa, por lo que es una gran opción para personas solteras o parejas jóvenes

- Áreas comunes. Los proyectos ofrecen comodidades dentro de casa como piscinas, gimnasios o áreas de parrilla

- Desventaja: falta de privacidad y autonomía" (Bolsalnmobiliaria.pe, s.f.) 


\subsubsection{Tecnológico}

En la actualidad el Internet se ha convertido en un medio indispensable para obtener información a nivel mundial. En el Perú el alcance del mismo se encuentra en crecimiento lento, pero con varias oportunidades para seguir desarrollándose. Según el Informe de Internet 2017 - Digital Marketing Toolkit Peru, 53\% de los peruanos ya hacen uso del Internet. (GFK, 2017)

\section{3\% de los peruanos ya hacen uso GFK
del Internet}

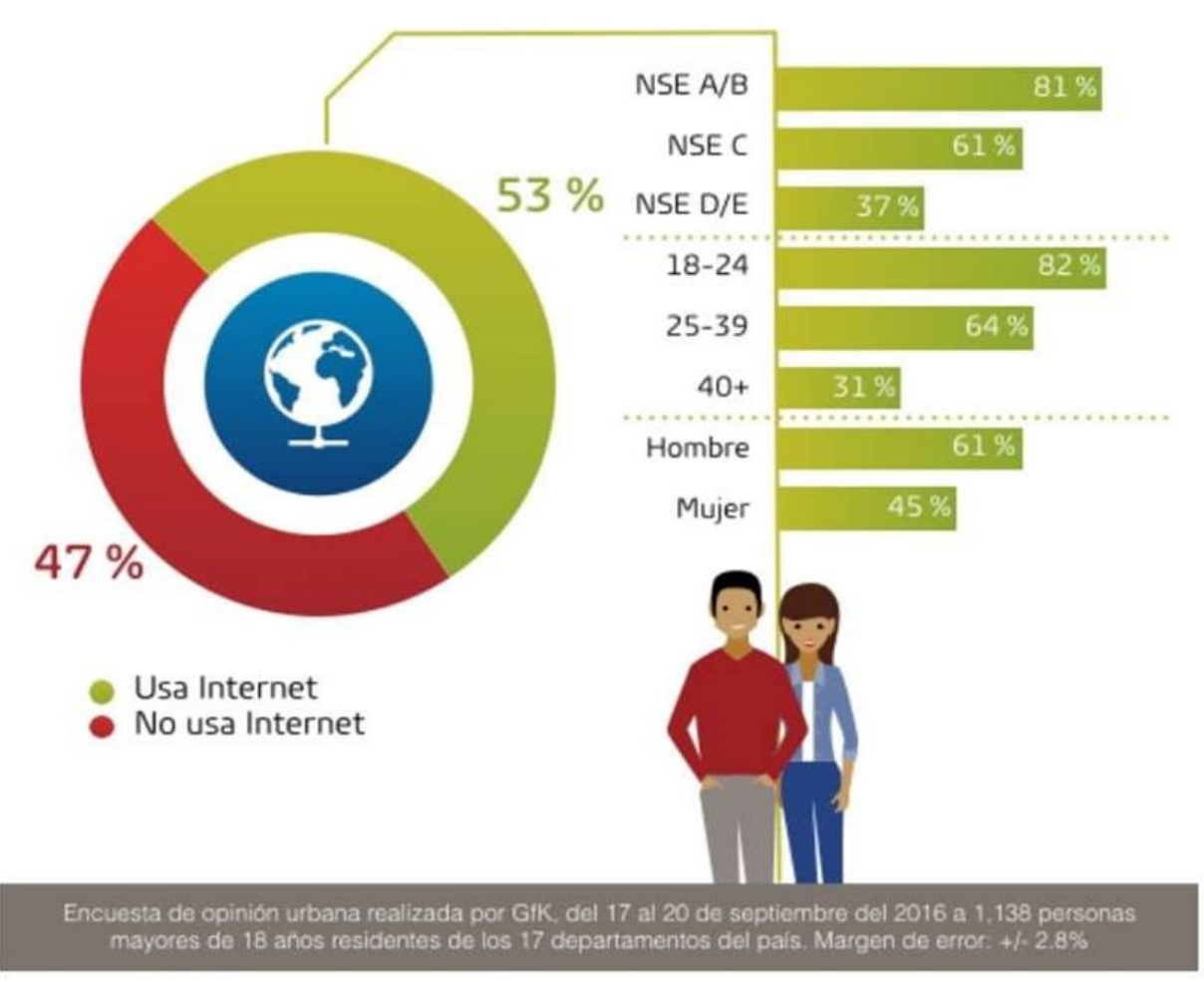

Figura 2. Informe de Internet 2017 - Digital Marketing Toolkit Peru. Fuente: GFK

A nivel de Provincia, Lima tiene una población de más de 9 millones al año 2018 (según estimaciones y proyecciones de población realizado por el INEI) (INEI, 2018). La última Encuesta Nacional de Hogares 2017 (ENAHO) arrojó que la población de Lima es la 
que mayor acceso a Internet tiene (67.7\%), lo que significaría que más de 5 milllones de limeños tienen acceso al mismo. (America TV, 2018)

En base a estos datos, sumado al crecimiento del mercado inmobiliario en el país, genera una demanda en ascenso de departamentos a través de plataformas digitales. Gracias a ello pueden consultar sobre los proyectos mismos, pueden dar recorridos virtuales y conocer los comentarios generados por clientes del mismo.

“De acuerdo a OLX Perú, hasta octubre del 2018, solo la categoría inmobiliaria recibió más de 23 millones de visitas en su portal web. Eso significa que en promedio fueron más de 2 millones de visitas de personas que desean alquilar o comprar un departamento o vivienda. Un alto número de personas interesadas en obtener información a través de las plataformas digitales como correos, publicaciones en redes sociales, entre otros." (ABRIL, 2019)

Según Abril Grupo Inmobiliario, las siguientes ciudades tienen la mayor oferta inmobiliaria online y a la vez un alto número de visitas: Lima, Trujillo y Arequipa. Un dato muy importante que nos brinda, es que el mercado inmobiliario tiene una penetración online de $20 \%$, lo cual genera grandes expectativas para el desarrollo del mismo en poco tiempo. (ABRIL, 2019)

\section{HALLAZGOS CLAVE}

\subsection{De la marca}

Los Juegos Panamericanos son el mayor evento deportivo internacional disciplinario, exclusivo para atletas de América. Es el segundo evento más importante para nuestro continente después de los Juegos Olímpicos. Además, se da un año antes a los Juegos Olímpicos de Verano. 
Las Últimas ediciones son:

- XV: 2007 - Brasil (Río de Janeiro)

- XVI: 2011 - México (Guadalajara)

- XVII: 2015 - Canadá (Toronto)

- XVIII: 2019 - Perú (Lima)

- XIX: 2023 - Chile (Santiago)

Para Lima 2019 (Panamericanos) se obtuvieron los siguientes datos:

- Países participantes: 41

- Total de deportistas: 6680

- Eventos: 420 divididos en 39 deportes

- Fecha de apertura: 26 de julio de 2019

- Fecha de clausura: 11 de agosto de 2019

- TOP 10 Medallero:

\section{JUEGOS PANAMERICANOS}

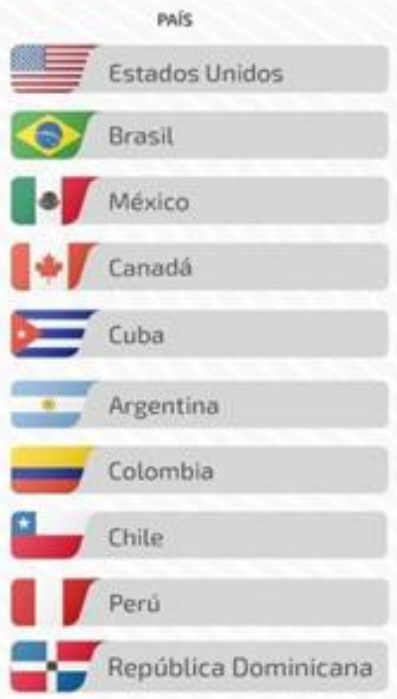

\begin{tabular}{|l|l|l|}
\hline 120 & 88 & 85 \\
\hline 55 & 45 & 71 \\
\hline 37 & 36 & 63 \\
\hline 35 & 64 & 53 \\
\hline 33 & 27 & 38 \\
\hline 32 & 35 & 34 \\
\hline 28 & 23 & 33 \\
\hline 13 & 19 & 18 \\
\hline 11 & 7 & 21 \\
\hline 10 & 13 & 17 \\
\hline
\end{tabular}


Desde 2007, la ciudad escogida como sede de los juegos organiza tanto los Panamericanos como los Parapanamericanos. Los Juegos Parapanamericanos se celebran inmediatamente después que culminan los Juegos Panamericanos (en el mismo año).

Para Lima 2019 (Parapanamericanos) se obtuvieron los siguientes datos:

- Países participantes: 30

- Total de deportistas: 1890

- Eventos: 369 divididos en 18 deportes

- Fecha de apertura: 23 de agosto de 2019

- Fecha de clausura: 1 de setiembre de 2019

- TOP 10 Medallero:

\section{JUEGOS PARAPANAMERICANOS}

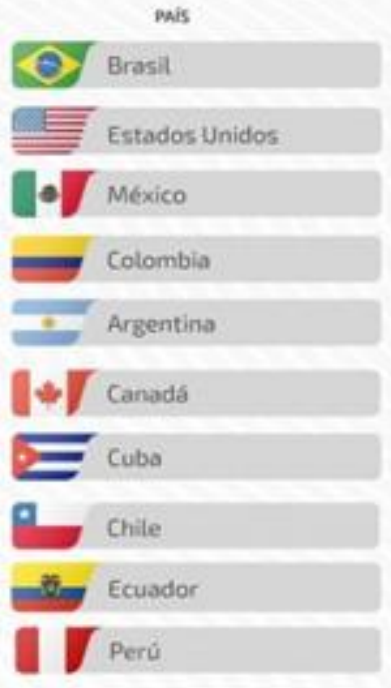

\begin{tabular}{|c|c|c|}
\hline 124 & nats & shonct \\
\hline 58 & 99 & 85 \\
\hline 55 & 62 & 65 \\
\hline 47 & 58 & 45 \\
\hline 26 & 36 & 50 \\
\hline 17 & 38 & 43 \\
\hline 13 & 21 & 22 \\
\hline 11 & 10 & 16 \\
\hline 5 & 12 & 11 \\
\hline 5 & 6 & 5 \\
\hline
\end{tabular}

Figura 4. El medallero completo de los Parapanamericanos Lima 2019. Fuente: El Comercio

Sobre los antecedentes de los Juegos Panamericanos y Parapanamericanos, a finales de enero de 2013 se cerró el plazo para presentar las candidaturas para organizar los Juegos Panamericanos de 2019. Fue en octubre del mismo año que Lima (Perú) fue escogida por la ODEPA (Organización Deportiva Panamericana) para realizar los 
Panamericanos, superando por amplio margen de votación a La Punta (Argentina), Santiago (Chile) y Ciudad Bolívar (Venezuela).

Todo esto ocurrió durante el gobierno del expresidente Ollanta Humala, pero el porcentaje de avances para el desarrollo del evento fue paupérrimo. No es hasta el 2016, con Pedro Pablo Kuzcynski como presidente, que se designó a Carlos Neuhaus como presidente del Comité Organizador de Lima 2019.

Hay que tomar en consideración que por diversos motivos (pocos avances a nivel de infraestructura, críticas en contra del presupuesto, el fenómeno de El Niño Costero en 2017) existió la posibilidad que nos retiraran la localía, lo cual hubiera creado un muy negativo precedente para el país a nivel mundial, sin contar las sanciones correspondientes. (Panamericana, 2019)

Según cifras oficiales, el Estado Peruano desembolsó 4,200 millones de soles (1,200 millones de dólares aprox.) para acondicionar todas las instalaciones requeridas (desde remodelaciones casi completas hasta construcciones edificadas desde cero), eventos requeridos, convenios, entre otras.

En el caso de la Villa Panamericana, el coste final fue de 270 millones de soles ( 80 millones de dólares). Inicialmente se había decidido construir 39 edificios de entre 8 y 10 pisos, pero para acelerar en los tiempos y reducir costes, quedó en 7 torres (4 torres de 20 pisos y 3 torres de 19 pisos). (Expreso, 2019)

Fue en el año 2017, que Carlos Neuhaus anunció que el consorcio Besco-Besalco (empresa chilena) sería la encargada de la construcción de la Villa Panamericana. De esta manera logró superar a empresas como Acciona Construcción S.A. (España), COSAPI S.A. (Perú), China Yingying Construcción Ingeniería Corporación (China), entre otras importantes en el rubro. (El Comercio, 2017)

Carlos Neuhaus indicó que la razón principal para la elección de Besco fue su experiencia de 18 años en el Perú y que había construido un complejo que se asemeja al Condominio Villa del Atleta. 
A inicios del 2020, los departamentos del Condominio Villa del Atleta serán puestos a la venta. Las características del condominio son las siguientes:

- Ubicación: Distrito Villa el Salvador, 5to Sector, área zonal 26 en el Complejo Biotecnológico Mz A.

- Total de departamentos: 1096

- Total de torres de vivienda: 7 (siete)

- De la torre 1 (uno) al 4 (cuatro): tiene total de 20 (veinte) pisos - cada piso con 8 (ocho) departamentos (desde 70 a 75 metros cuadrados) (4 torres $x$ 20 pisos $\times 8$ depas $=640$ departamentos)

- De la torre 5 (cinco) al 7 (siete): tiene en total de 19 (diecinueve) pisos - cada piso con 8 (ocho) departamentos (desde 70 a 75 metros cuadrados) (3 torres $\times 19$ pisos $\times 8$ depas $=456$ departamentos)

- De los 1096 departamentos, hay 336 diseñadas para fácil acceso para discapacitados (se encuentran en los primeros 12 pisos de las 7 torres). (7 torres $\times 12$ pisos $\times 8$ depas $=672 / 2=336$ departamentos)

- Cada departamento cuenta con: 3 dormitorios + sala + comedor + cocina + 2 Baños

- Cada torre cuenta con doble sótano. La construcción también incluyó todas las obras mecánicas, eléctricas y de gasfitería para las torres, así como ascensores, áreas verdes, rutas vehiculares y peatonales.

- Además de las viviendas, la Villa Panamericana tiene infraestructuras temporales como comedor, oficinas administrativas, Policlínico, Iglesia, Centros Culturales, Gimnasio, Centro de Prensa, Anfiteatro, Piscina, Pista de jogging. Cabe resaltar que todas estas implementaciones quedarán de manera permanente excepto la piscina, por el costo de mantenimiento. Los departamentos tendrán algunas modificaciones que serán concluidas en diciembre del presente año para que esta Villa se convierta en un gran condominio de viviendas familiares

- Los deportistas peruanos que obtuvieron una presea se harán acreedores de un departamento en la Villa Panamericana y también de un premio monetario.

- Previo al inicio del evento deportivo, el presidente de la República, Martín Vizcarra, aprobó el reglamento de la Ley № 30949 que establece premios a los atletas peruanos que hayan alcanzado un lugar en el podio. 
La adjudicación de viviendas se realizará de acuerdo al tipo de medalla que hayan obtenido los deportistas:

- A los/las atletas medallistas de oro: departamentos de $75.83 \mathrm{~m} 2$.

- A los/las atletas medallistas de plata: departamentos de $73.83 \mathrm{~m} 2$.

- A los/las atletas medallistas de bronce: departamentos de $70.87 \mathrm{~m} 2$.

- A los/las atletas paralímpicos medallistas de oro, plata o bronce: departamentos de $75.83 \mathrm{~m} 2$.

Los Ganadores de departamentos en Condominio Villa de Atletas fueron los siguientes: por medalla de oro (13), por medalla de plata (7), por medalla de bronce (26) y por medalla de Parapanamericanos. (15)

Haciendo los cálculos finales, el total de departamentos que irían a la venta son:

714 departamentos no inclusivos en total para la venta y $\mathbf{3 2 1}$ departamentos inclusivos en total para la venta (1035 en total).

Determinar la cantidad de departamentos en venta es importante para la realización de la estrategia digital que se basa en Performance. Así, destinamos un $39 \%$ de la inversión total de digital hacia acciones que generen Leads. En total estamos proyectando 4060 leads, que son importantes para el objetivo comercial. Explicaremos más al detalle estas acciones en el mix de medios.

\subsection{Del Mercado}

El mercado inmobiliario se encuentra en un buen momento este año. El precio por metro cuadrado estaría aumentando en 5 y $8 \%$ al cierre del 2019. Esto debido a la estabilidad económica y a la demanda.

"Lima es un mercado con muchísima demanda inmobiliaria, se estima que hay 190,000 familias que pueden adquirir viviendas solo en esta ciudad, mientras que hay una oferta constante de 20,000 unidades al mes. Esta demanda debería originar este incremento de precios" (GESTIÓN, 2019) 
En cuanto a la región, Perú conserva el precio por m2 más barato. En el caso de Lima, los distritos de Barranco, San Isidro, Miraflores y San Borja tienen los precios más altos por m2, mientras que los distritos más alejados tienen el menor precio.
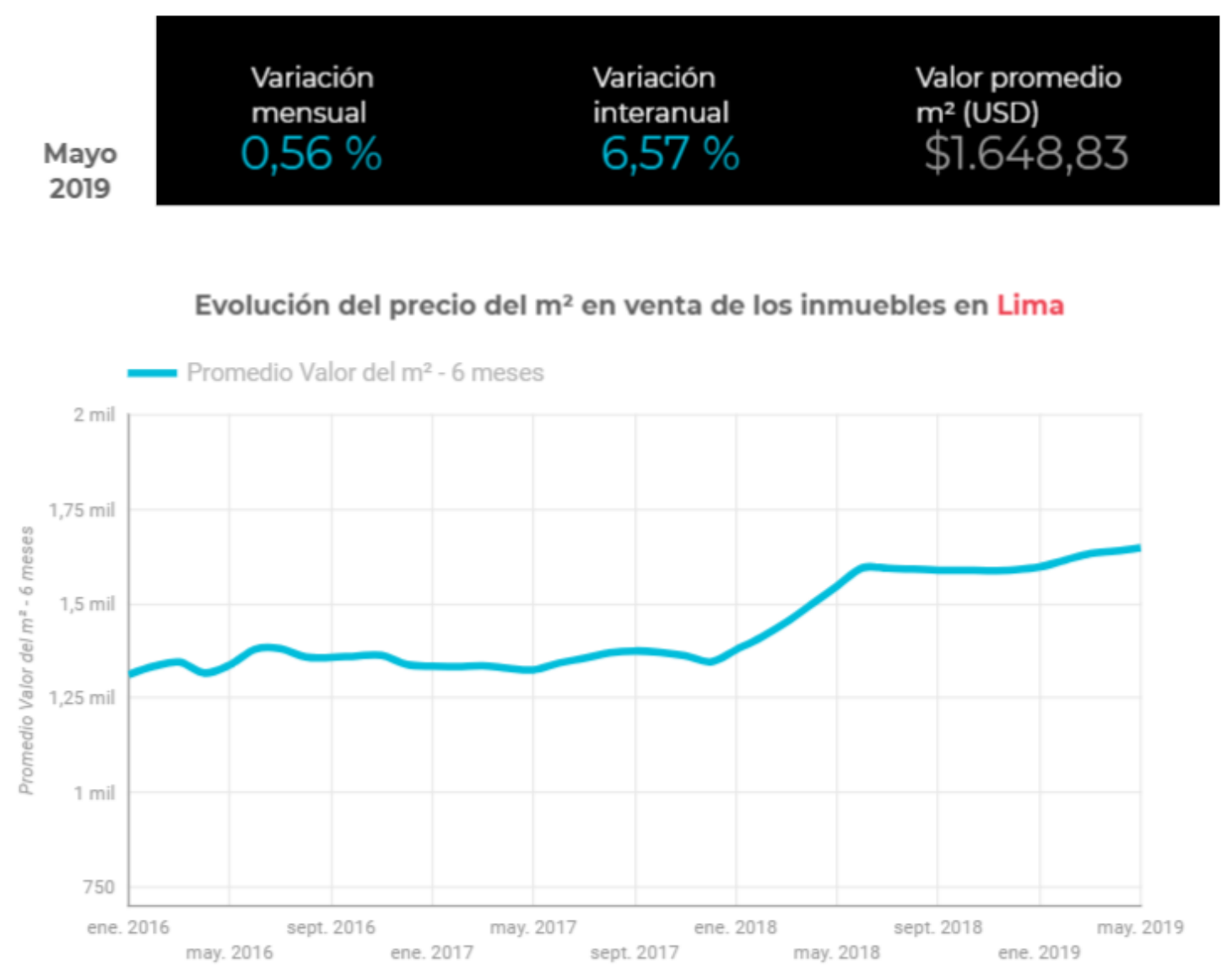

Figura 5. Reporte del Mercado Inmobiliario - Lima Junio 2019. Fuente: Properati Blog

Se sabe que los limeños prefieren departamentos de 3 dormitorios. Usualmente buscan departamentos aledaños al lugar donde viven actualmente. Un mercado potencial son los solteros. 


\subsection{De la Competencia}

Actualmente en el distrito de Villa El Salvador solo existen dos condominios de departamentos (excluyendo la Villa Panamericana): "Los Parques de Villa El Salvador" y "Los Parques de Villa El Salvador II". Ambos proyectos realizados por la inmobiliaria VIVA GyM hace más de 4 años, y con la opción de comprarlos mediante el Bono de Nuevo Crédito MiVivienda.

En comunicación telefónica directa con un representante de VIVA GyM, se nos informó que el $100 \%$ de los departamentos de ambos condominios ya han sido vendidos, por lo que, aunque ya no es considerado una competencia directa, igual nos ayuda a tener una idea de lo ofrecido como condominio hacia el público.

Los Parques de Villa El Salvador:

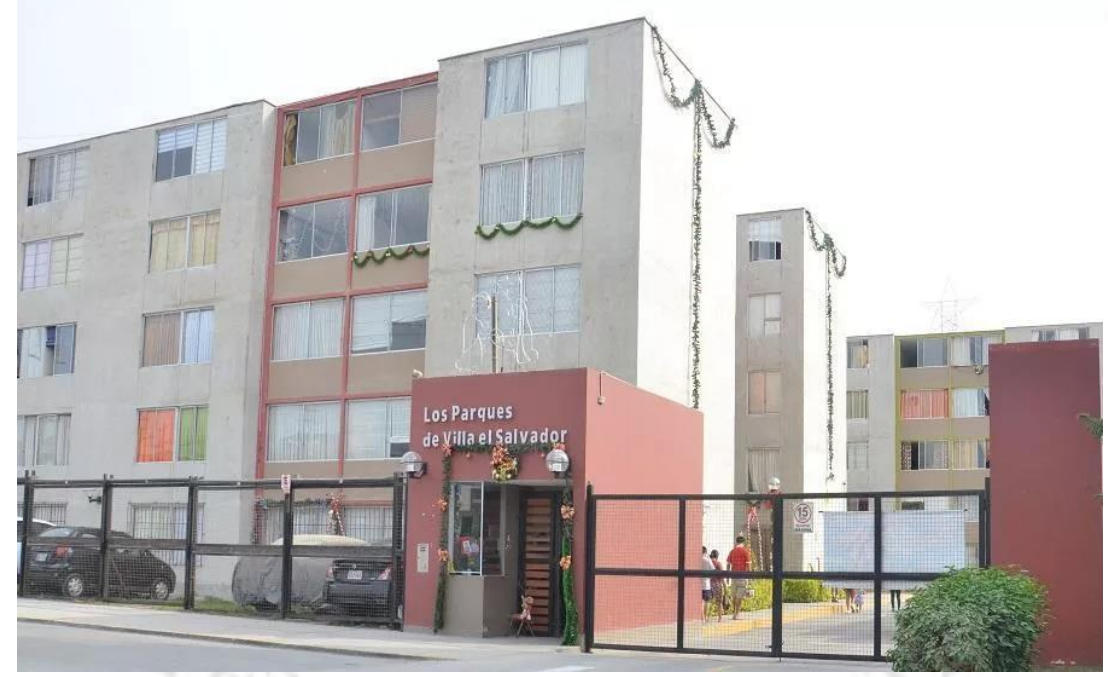

Imagen 1. Los Parques de Villa El Salvador. Fuente: OLX 


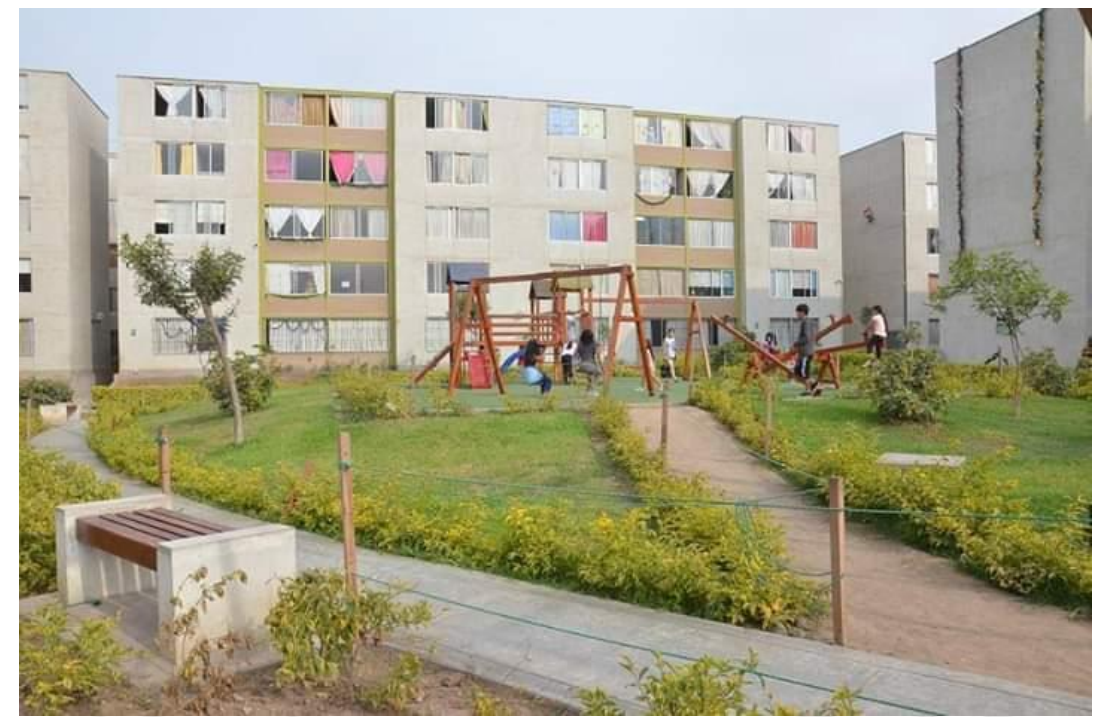

Imagen 2. Los Parques de Villa EI Salvador. Fuente: OLX

Los Parques de Villa El Salvador 2:

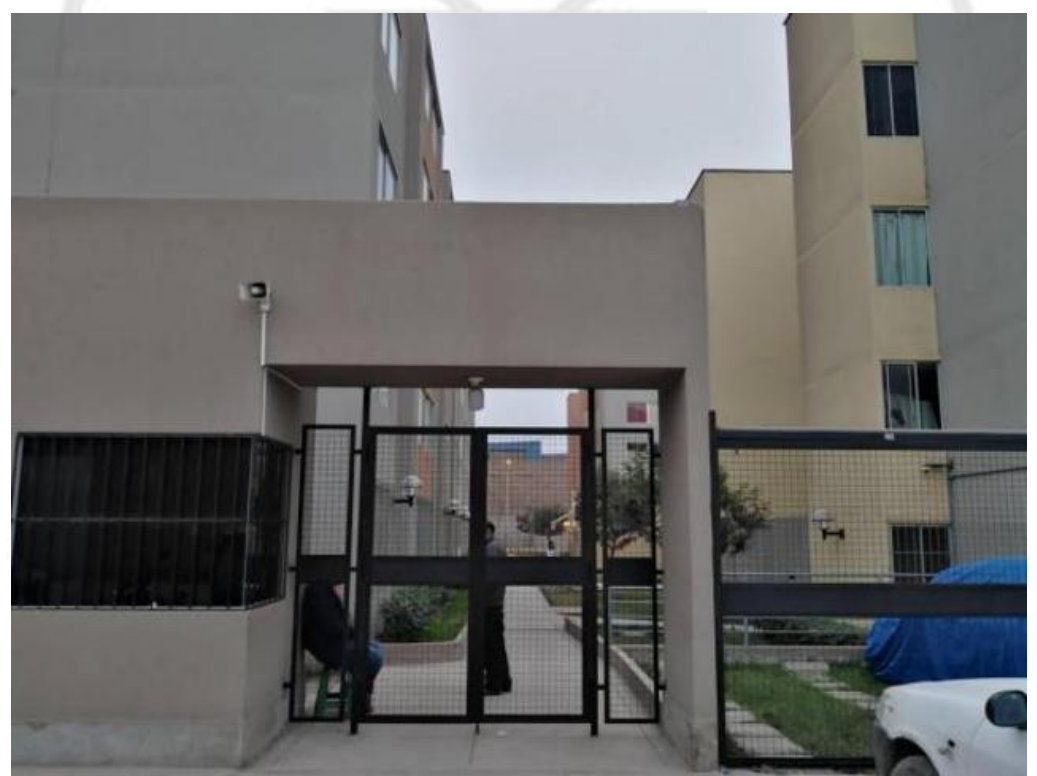

Imagen 3. Los Parques de Villa El Salvador 2. Fuente: OLX 


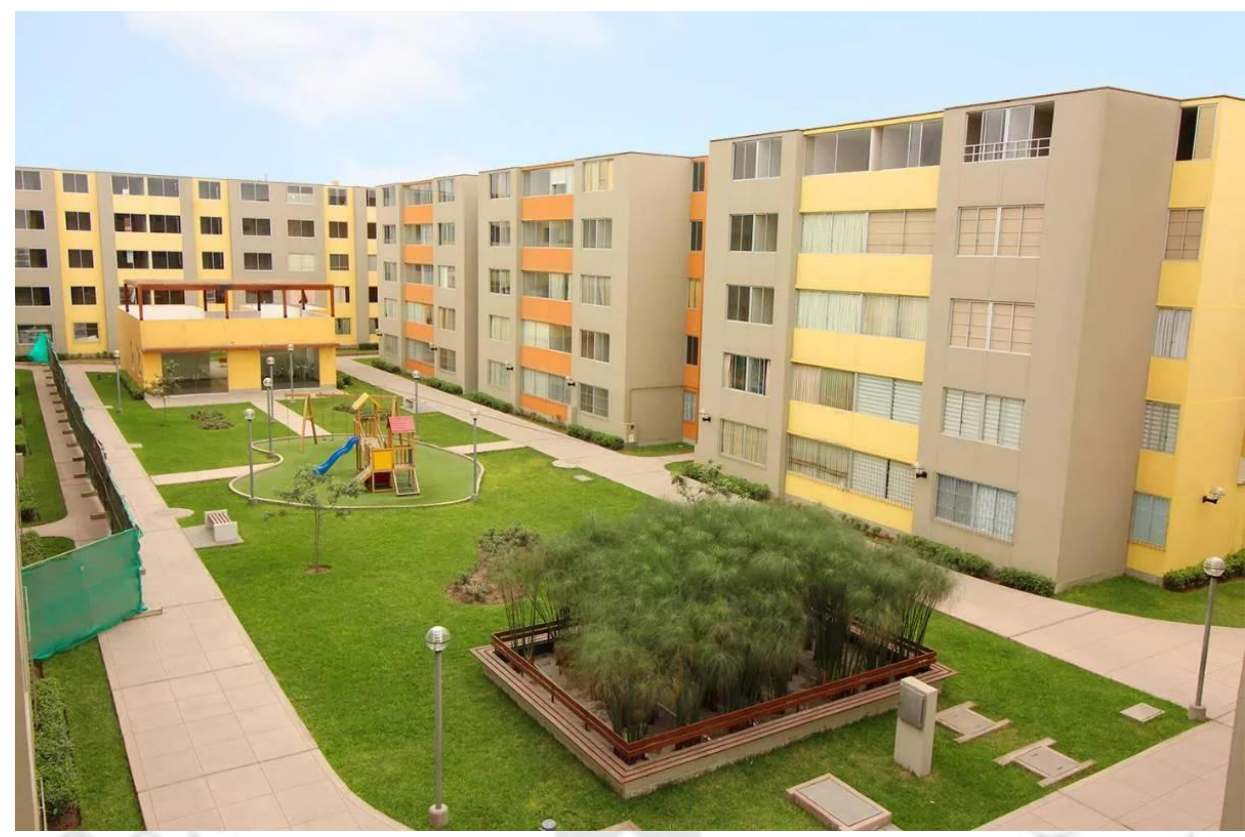

Imagen 4. Los Parques de Villa El Salvador. Fuente: OLX
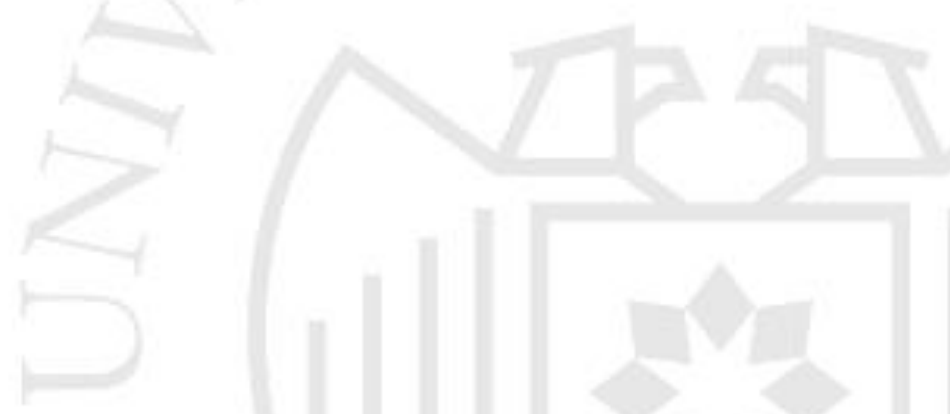

Ambos condominios tienen características muy parecidas:

- Departamentos de aproximadamente $60 \mathrm{~m}^{2}$

- Edificios de 5 pisos

- 2 porterías para control de ingreso peatonal y/o vehicular

- Cámaras de vigilancia alrededor del condominio

- Distribución interior de departamentos: (3) Dormitorios; Sala/Comedor; Cocina/Lavandería; (1) Baño (algunos 2)

- No todos los departamentos cuentan con estacionamiento

- Más de $1000 m^{2}$ de áreas verdes interiores (con zona de juegos para niños)

- Club House (Sala de usos múltiples, (1) Local Comercial, Terraza)

- No cuentan con ascensor

Como dato adicional podemos encontrar que "Los Parques de Villa El Salvador" se encuentra rodeado de pistas asfaltadas, se encuentra al frente del Mercado Mayorista Plaza Unicachi Sur y si cruzas la pista está el centro comercial MegaPlaza. En el año 2014, el programa Panorama (Panamericana Televisión) emitió un reportaje en donde 
hablaba de las quejas que recibió este condominio por parte de los propietarios por no contar con las condiciones de construcción estipuladas por la inmobiliaria y sentirse estafados en ese aspecto. (Link del video: https://www.youtube.com/watch?v=GUPBgmwe4E8)

Por el otro lado, "Los Parques de Villa El Salvador 2" se encuentra a unas cuadras más abajo del otro condominio, pero no cuenta con pistas asfaltadas (trocha con huecos, y donde una gran cantidad de tierra se levanta con el paso de los autos), se encuentra frente a empresas industriales y hay zonas de descampado a los alrededores.

Como otra competencia indirecta encontramos la venta de casas y departamentos, los cuales no se ha podido encontrar gran oferta desde el punto de observación visual a través del distrito. Lo poco observado fueron anuncios pegados en postes o paredes de casas muy básicos y sin respaldo de un corredor inmobiliario.

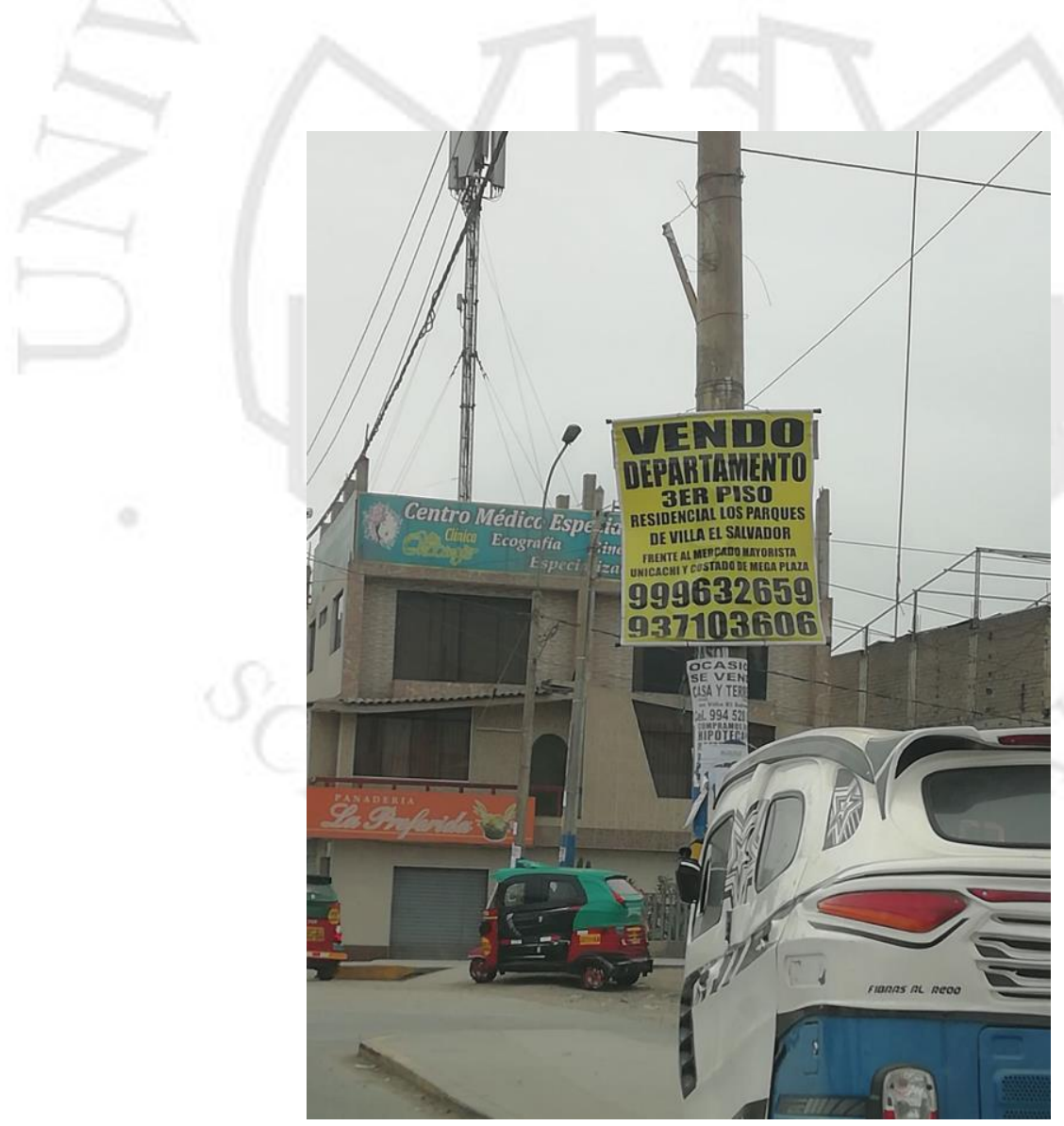

Imagen 5. Distrito Villa El Salvador. Fuente: propia 


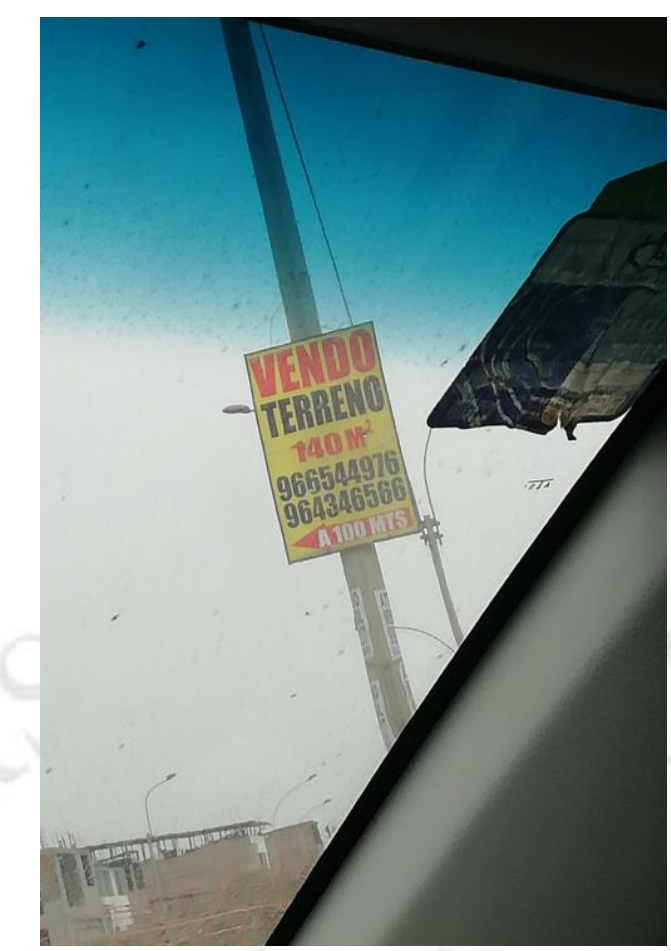

Imagen 6. Distrito Villa El Salvador. Fuente: propia
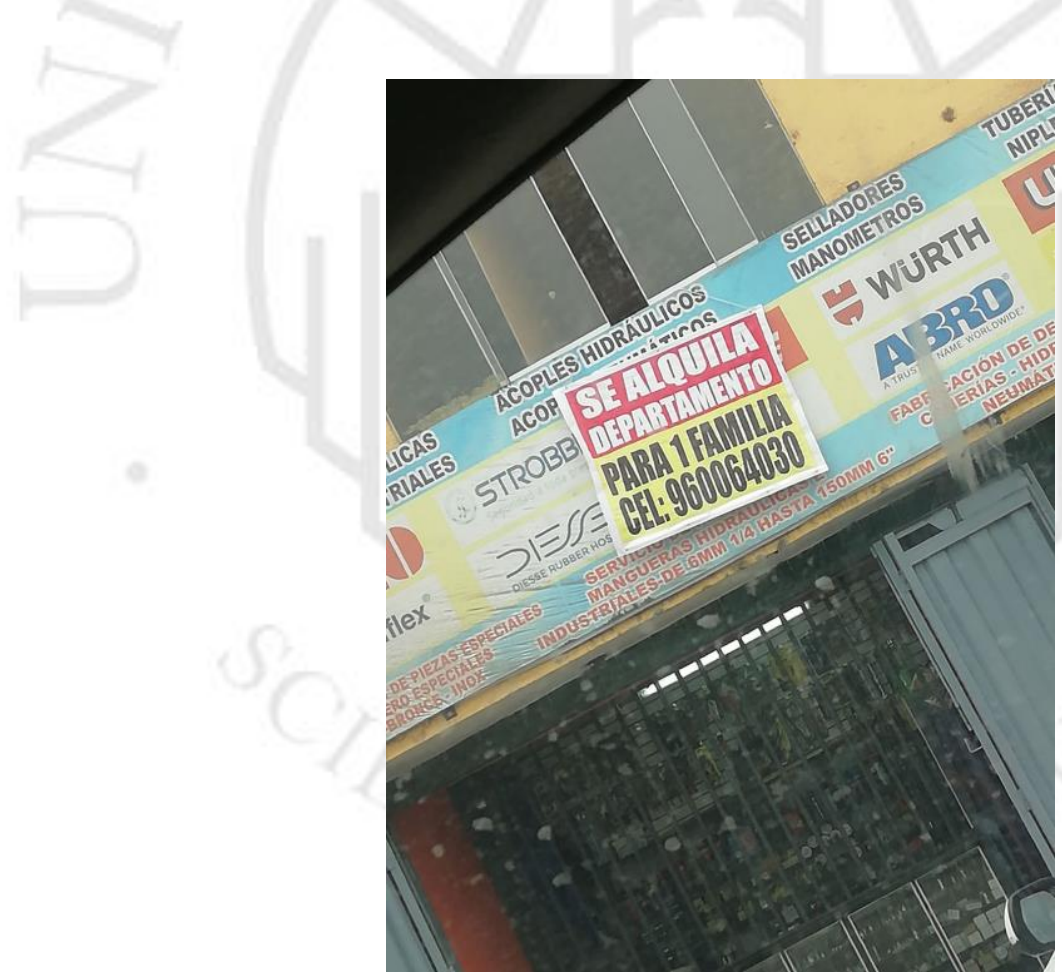

Imagen 7. Distrito Villa El Salvador. Fuente: propia 


\section{Público Objetivo}

El Condominio Villa del Atleta se encuentra ubicado en el distrito de Villa El Salvador, por lo que ya nuestro universo de posibles compradores estará en su mayoría concentrado en este mismo distrito y en distritos aledaños (Villa María del Triunfo y San Juan de Miraflores). Por lo que consideramos necesario mostrar información estadística de los distritos en mención para tener un panorama más claro. La información mostrada fue presentada por el Instituto Nacional de Estadística e Informática (INEI), mediante el documento "Resultados Definitivos de la Provincia de Lima" (los resultados del documento en mención fueron producto de los Censos Nacionales 2017): (INEI, 2018)

Villa El Salvador y distritos aledaños:

- Cuenta con una población de 393,254 habitantes (Villa María del Trinfo = 398,433; San Juan de Miraflores = 355,219)

- Villa María del Triunfo (4,7\%), Villa el Salvador (4,6\%) y San Juan de Miraflores $(4,2 \%)$ se encuentran dentro de los distritos que agrupan la mayor población del área urbana $(50,2 \%)$ de la provincia de Lima. La totalidad de la población de Villa El Salvador es urbana (5to puesto dentro de todos los distritos de Lima en tener la mayor población del área urbana)

- Villa El Salvador: 279,389 habitantes son mayores de edad (71\% del total)

- Villa El Salvador: 304,936 habitantes tienen edad para trabajar (77.5\% del total)

- Villa El Salvador: $52.3 \%$ tiene secundaria y 32.6\% educación superior (números muy similares en distritos aledaños)

- Villa El Salvador: el promedio de hijos es de 1.3 (números muy similares en distritos aledaños)

- Villa El Salvador: 43,345 habitantes cuentan con alguna dificultad o limitación permanente (números muy similares en distritos aledaños)

- Villa El Salvador: 193,833 son hombres y 199,421 son mujeres

- Villa El Salvador: un total de 188,097 habitantes (47\% del total) pertenecen a los rangos de edad entre 25 hasta los 59 años. De 25 hasta 34 años $=66,764$ (17\% del total). De 35 hasta los 59 años $=121,333$ (30\% del total)

- Villa El Salvador: 369,408 habitantes cuentan con casa independiente (93\% del total); 17,218 con departamento ( $4.3 \%$ del total) 
- Villa El Salvador: 130,470 son solteros (33\%); 86,128 son convivientes (21\%); 15,410 son separados (3.9\%); 74,276 son casados (18\%); 9,310 son viudos (2.4\%); 2,292 son divorciados $(0.58 \%)$

En un principio habíamos decidido dividir a nuestro público objetivo en tres grandes grupos: Adulto Joven del NSE C y D que vivan en el distrito de Villa EI Salvador y distritos aledaños (el rango de edad del Adulto Joven es de 21 a 35, pero nos enfocaremos desde los 25 en adelante); Adulto del NSE C y D que vivan en el distrito de Villa El Salvador y distritos aledaños (el rango de edad del Adulto es de 36 a 59 años); y personas con Discapacidad en el Perú. Pero en base a los resultados obtenidos mediante estudios de Ipsos, Inei y encuestas propias realizadas; decidimos enfocar toda nuestra fuerza de trabajo en dos: hacia el Adulto Joven del NSE C y D (25 a 35 años en concreto) y Adulto del NSE C y D (ambos grupos de Villa El Salvador y distritos aledaños).

Le damos un pequeño énfasis extra al Adulto Joven por los siguientes puntos, pero no por ello descuidamos al Adulto:

- Más del $60 \%$ no cuenta con una vivienda. Esto es vital porque para poder acceder al Nuevo Crédito Mivivienda no puedes ser propietario o copropietario de otra vivienda a nivel nacional

- Más del $60 \%$ se encuentra vinculado sentimentalmente con otra persona (conviviente, con pareja, casado, con hijos), lo que significa que están en proceso de decidir formar una familia o ya la tienen, y parte de ello conlleva tener un espacio propio

- Más del $60 \%$ de la población que trabaja lo hace de forma dependiente, y actualmente muchas empresas exigen que uno se afilie a un banco por diferentes razones (pago de sueldo por ejemplo)

- Aunque es cierto que un poco menos del $40 \%$ se encuentra bancarizado, año a año el porcentaje de No Bancarizados desciende (2017: 65\%; 2018: $61 \%$ ), lo que genera expectativas positivas para este campo. Esto es muy importante a la hora de querer acceder al Nuevo Crédito Mivivienda, el cual 
exige ser calificado por la Entidad Financiera a través de la cual te harán el préstamo necesitado.

- El ingreso mensual medio está por encima de los 1000 soles, y casi el $30 \%$ ahorra principalmente para comprar una casa/departamento/terreno. A pesar de quizás no ser un monto tan elevado, el Nuevo Crédito Mivivienda permite financiar viviendas en plazos de pago de 5 a 20 años con cuotas mensuales que permitirían poder pagarlas sin llegar a comprometer otros gastos prioritarios.

De igual manera consideramos importante mencionar los hallazgos más importantes en el grupo de personas con discapacidad, debido a que puede llegar a representar un porcentaje de las ventas totales (quizás no un porcentaje tan importante, pero nuestro objetivo es vender la totalidad de los departamentos). De los 3 grupos escogidos, hay que tomar en consideración que no existen grandes datos sobre personas con Discapacidad.

La siguiente información fue obtenida mediante el informe "Perfil del adulto joven peruano" (IPSOS, 2018) y el informe "Gen X: Perfil del adulto" (IPSOS, 2019).

\subsection{Perfil Demográfico y familiar}

Adulto Joven: (Fuente: Perfil del adulto joven peruano - 21 a 35 años - Perú Urbano, 2018)

- Hay un total de 6,267,908 Adulto Joven de Perú Urbano de 21 a 35 años, lo que representa al $25 \%$ de la población total del Perú Urbano (más de 25 millones). De los más de 6 millones, casi 4 millones se encuentran en el rango de 26 a 35 años.

- $\quad 48 \%$ son hombres y $52 \%$ mujeres

- El promedio de edad es de 27 años

- $33 \%$ son soltero sin pareja; $27 \%$ conviviente; $24 \%$ soltero con pareja; $11 \%$ casado

- De mayor a menor: 33\% pertenece al NSE C; $29 \%$ al D; $18 \%$ al E; $17 \%$ al B; $3 \%$ al $\mathrm{A}$

- 3 de cada $5(60 \%)$ son padres y tienen en promedio un hijo 
- $44 \%$ tiene Secundaria completa / Superior técnico incompleta (aquí encontramos en mayor porcentaje al NSE C con $50 \%$ y al NSE D con 59\%); 22\% Superior Técnico Completa; 17\% educación Superior Universitaria completa

- Las metas más importantes que aspiran es tener trabajo (79\%); tener casa propia (78\%); y tener estudios (80\%)

- $52 \%$ sigue viviendo con los padres (NSE D: $57 \%$ ) y $19 \%$ tiene una vivienda alquilada (NSE C: $27 \%$ )

- 30 años es la media general de edad para independizarse

Adulto: (Fuente: Gen X: Perfil del Adulto - 36 a 59 años - Perú Urbano, 2019)

Hay un total de 7,122,504 Adultos del Perú Urbano de 36 a 59 años, lo que representa al $28 \%$ de la población total del Perú Urbano.

$49 \%$ son hombres y $51 \%$ mujeres

El promedio de edad es de 46 años

$33 \%$ es casado; $25 \%$ conviviente; $20 \%$ soltero sin pareja; $9 \%$ separado; y $8 \%$ soltero con pareja

- De mayor a menor: 36\% pertenece al NSE C; $30 \%$ al D; $16 \%$ al B; $15 \%$ al E; $3 \%$ al $A$

- $82 \%$ tienen hijos. El promedio general es de 2 hijos. El promedio de edad de los hijos es de 17 años

- 39\% tiene Secundaria Completa/Superior Técnico Incompleta; 21\% tienen Superior Universitaria Completa

\subsection{Perfil Laboral}

Adulto Joven:

- $65 \%$ Solo trabaja; $19 \%$ trabaja y estudia; $14 \%$ no trabaja ni estudia; $2 \%$ solo estudia

- $61 \%$ es trabajador dependiente; $22 \%$ es trabajador independiente; $12 \%$ trabaja en casa; $3 \%$ es desempleado; y $2 \%$ es estudiante

- Del porcentaje que trabaja: $47 \%$ trabaja en una empresa privada (siendo mayor porcentaje el NSE A (67\%) y NSE B (65\%)); 26\% trabaja de forma independiente (siendo mayor porcentaje el NSE E (41\%); $21 \%$ trabaja en 
una empresa pública (siendo mayor porcentaje el NSE D (31\%)); 5\% es dueño de una empresa (negocio)

- En promedio, trabajan 45 horas a la semana

- $37 \%$ trabaja en algo diferente a lo que ha estudiado (40\% representado por los NSE BCD); $36 \%$ trabaja en lo que ha estudiado (mayor \% representado por los NSA AB); $27 \%$ trabaja, pero no ha estudiado nada aún (mayor \% representado por NSE E, pero los NSE CD tienen un \% considerable)

- $\quad$ EI NSE CD prefieren tener su propio negocio; el NSE B quiere pertenecer a una gran empresa; y el NSE A anhela no trabajar

Adulto: (Fuente: Gen X: Perfil del Adulto - 36 a 59 años - Perú Urbano, 2019)

- $77 \%$ Sólo trabaja; $16 \%$ No trabaja ni estudia; $7 \%$ trabaja y estudia

- $53 \%$ es trabajador dependiente; $31 \%$ trabajador independiente; $12 \%$ trabaja en casa; $4 \%$ es desempleado

Uno de cada diez tiene un negocio (16\%); y casi la mitad de ellos se consideran a sí mismos como emprendedores (48\%)

- Entre aquellos que no tienen negocio (84\%), 7 de 10 quisiera iniciar uno $(69 \%)$

\subsection{Perfil económico y financiero}

Adulto Joven:

- Las remuneraciones quincenales o mensuales son la principal fuente de ingresos (59\% del total), pero es percibido por los NSE más altos, mientras que los de nivel medio bajo cobran con frecuencia diaria 0 semanal (28\%)

- El ingreso mensual medio es de s/. 1,200. EI NSE C tiene una media de $\mathrm{s} / .1,200$, mientras el NSE $D$ recibe $\mathrm{s} / .1,000$

- El trabajador dependiente tiene una media de s/. 1,300, mientras un trabajador independiente recibe s/. 1,100.

- $\quad 73 \%$ del total ahorra una parte de sus ingresos y la otra parte la gasta

- El principal gasto está en Alimentación/Comida/Víveres (40\%) y el principal ahorro es para comprar una casa/departamento/terreno (29\%) 
- El nivel de bancarización es de 39\%. El 32\% son clientes de una entidad bancaria (NSE C: $31 \%$ ). El $61 \%$ no está bancarizado (NSE C: $60 \%$; NSE: $72 \%)$

- El Préstamo o crédito personal es el producto financiero más usado por el NSE C (22\%) y el NSE D (38\%)

- $94 \%$ no tiene vehículo propio

Adulto: (Fuente: Gen X: Perfil del Adulto - 36 a 59 años - Perú Urbano, 2019)

- El ingreso mensual medio es de s/.1,200. EI NSE C tiene una media de $\mathrm{s} / .1,500$, mientras el NSE D recibe $\mathrm{s} / .900$

- El trabajador dependiente tiene una media de s/. 1,500, mientras un trabajador independiente recibe s/. 1,000.

$62 \%$ ahorró; mientras un $49 \%$ se endeudó

- El nivel de bancarización es de $55 \%$. El $47 \%$ son clientes de una entidad bancaria (NSE C: $56 \%$ )

La cuenta de ahorros de sueldo o jubilación (55\%) y la tarjeta de débito (54\%) son los productos financieros de mayor tenencia

- $14 \%$ usa la bicicleta como vehículo; $9 \%$ usa moto; $8 \%$ usa auto o camioneta; y $69 \%$ indica no contar con ninguno

- 7 de cada 10 cuentan con algún seguro. El de Salud Pública es el de mayor tenencia (57\%)

- $\quad 33 \%$ está afiliado a la AFP; mientras un $57 \%$ no posee ningún fondo de pensión

\subsection{Entretenimiento y consumo de medios}

Adulto Joven:

- El principal medio de entretenimiento en casa es la Televisión (55\%)

- Para divertirse fuera de casa, prefieren salir a comer (43\%); pasear en parques (38\%); hacer ejercicio/deportes (37\%); o ir al cine (34\%)

- $56 \%$ mira televisión todos los días de la semana; $48 \%$ escucha radio todos los días de la semana; y solo $27 \%$ (3 de cada 10) lee periódicos todos los días de la semana 
Adulto:

- La actividad principal para divertirse fuera de casa es salir a comer (45\%) (Para el NSE C representa el 58\% y para el NSE D representa el 34\%)

- La televisión (59\%) es la principal actividad para divertirse dentro de casa (Para el NSE C representa el $68 \%$ y para el NSE D representa el $60 \%$ )

- $\quad 55 \%$ prefiere quedarse en casa en lugar de salir ( 6 de cada 10 )

- $\quad 88 \%$ ve televisión nacional; $84 \%$ escucha radio; $70 \%$ lee periódicos; $50 \%$ ve televisión de cable

\subsection{Comportamiento Tecnológico}

Adulto Joven:

- $85 \%$ son digitales; y se conectan a Internet en promedio 6 veces a la semana

$78 \%$ (3 de cada 4) es miembro de una red social, siendo Facebook $(76 \%)$ y WhatsApp (52\%) las más populares

- La tenencia de una red social tiene un porcentaje de $86 \%$ en el NSE C; y en el NSE D llega al $70 \%$

- A pesar de ser digitales, la mayoría (77\%) no compra por Internet. El NSE C solo lo hace en un $16 \%$; y el NSE D en un $7 \%$

- $\quad 24 \%$ tiene cuenta de NETFLIX; $18 \%$ tiene cuenta en Spotify

- $\quad 94 \%$ posee un celular; pero solo $61 \%$ tiene un smartphone (6 de cada 10)

- $\quad 40 \%$ tiene un televisor Smart TV; 34\% posee una laptop

Adulto:

- $\quad 72 \%$ son digitales. Dentro del mismo, $47 \%$ usa internet todos los días de la semana

- $\quad 70 \%$ tiene una red social (NSE C: $85 \%$ )

- Facebook es la red social más usada (66\%); 2do Youtube con $56 \%$; 3ro Google con 53\%; y 4to Web de noticias con $40 \%$

- En los últimos 12 meses, el 82\% no compró por Internet (en caso llegara a comprar, lo principal sería comida rápida en un 6\%)

- $88 \%$ tiene un celular; y dentro de este porcentaje, sólo el $50 \%$ tiene un smartphone 


\subsection{Información de personas con discapacidad física}

Hemos tenido que crear una sección aparte para este punto debido a que no existe una gran cantidad de estudios y estadísticas del mismo. En el Censo 2017 se pudieron conseguir algunas cifras, pero de tipo general sin hacer preguntas especializadas, por lo que sólo se conoció lo siguiente: (RPP, 2018)

- En el Perú existen 3,051,612 personas con discapacidad (10.4\% de la población total)

- $\quad 57 \%$ son mujeres; $43 \%$ son hombres

- $\quad 48 \%$ tiene discapacidad visual; $15.1 \%$ tiene discapacidad física; y el $7.6 \%$ discapacidad auditiva

El estudio previo más importante sobre este tema fue realizado por el INEI en el 2012, en la Encuesta Nacional Especializada sobre Discapacidad (ENEDIS). Podemos encontrar algunos datos importantes del mismo, los cuales tienen validez a pesar de la antigüedad de los mismos (tomando en cuenta que son los más fiables): (INEI, 2015)

- Lima es el departamento con mayor incidencia de la discapacidad (6.7\%)

- 64\% estudió solo hasta la Primaria; $22,4 \%$ secundaria; $4.7 \%$ superior no universitaria; y $6.9 \%$ cuenta con superior universitaria

- $47.6 \%$ de la población con discapacidad del sector urbano es Casado o Conviviente

- $61.2 \%$ se encuentra afiliada a algún Seguro de Salud

- $\quad 21.7 \%$ pertenece a la Población Económicamente Activa (PEA)

- $\quad 58.2 \%$ es trabajador independiente; mientras que solo $15.3 \%$ son empleados

Al no haber datos más actualizados, y tomando en cuenta la información obtenida por artículos periodísticos, videoreportajes, etc, podemos decir que, a pesar de los avances realizados en los últimos años, aún somos un país que tiene bastante por hacer antes de ser considerados como verdaderamente inclusivos. 


\subsection{Encuestas y Entrevistas}

Se decidió realizar 2 encuestas diferentes: A ciudadanos del distrito de Villa el Salvador de 25 a 55 años (50 encuestas); y a personas que vivan en los departamentos de los condominios Los Parques de Villa El Salvador 1 y 2 (40 en total dividido en 20-20 para cada condominio). También se realizó una entrevista telefónica con un representante del CONADIS (Consejo Nacional para la Integración de la Persona con Discapacidad). Entre los resultados más importantes encontramos lo siguiente:

Encuestas a ciudadanos del distrito de Villa El Salvador:

Pregunta 1: 52\% (26 personas) tienen de 25 a 35 años; 26\% (13 personas) tienen de 36 a 45 años; $22 \%$ (11 personas) tienen de 46 a 55 años

Pregunta $2: 70 \%$ (35 personas) trabaja para una empresa (dependiente)

Pregunta 3: El 66\% (33 personas) no es propietario de una vivienda

Pregunta 4: El 36\% tiene pareja e hijos; $28 \%$ pareja sin hijos; y el $20 \%$ es soltero

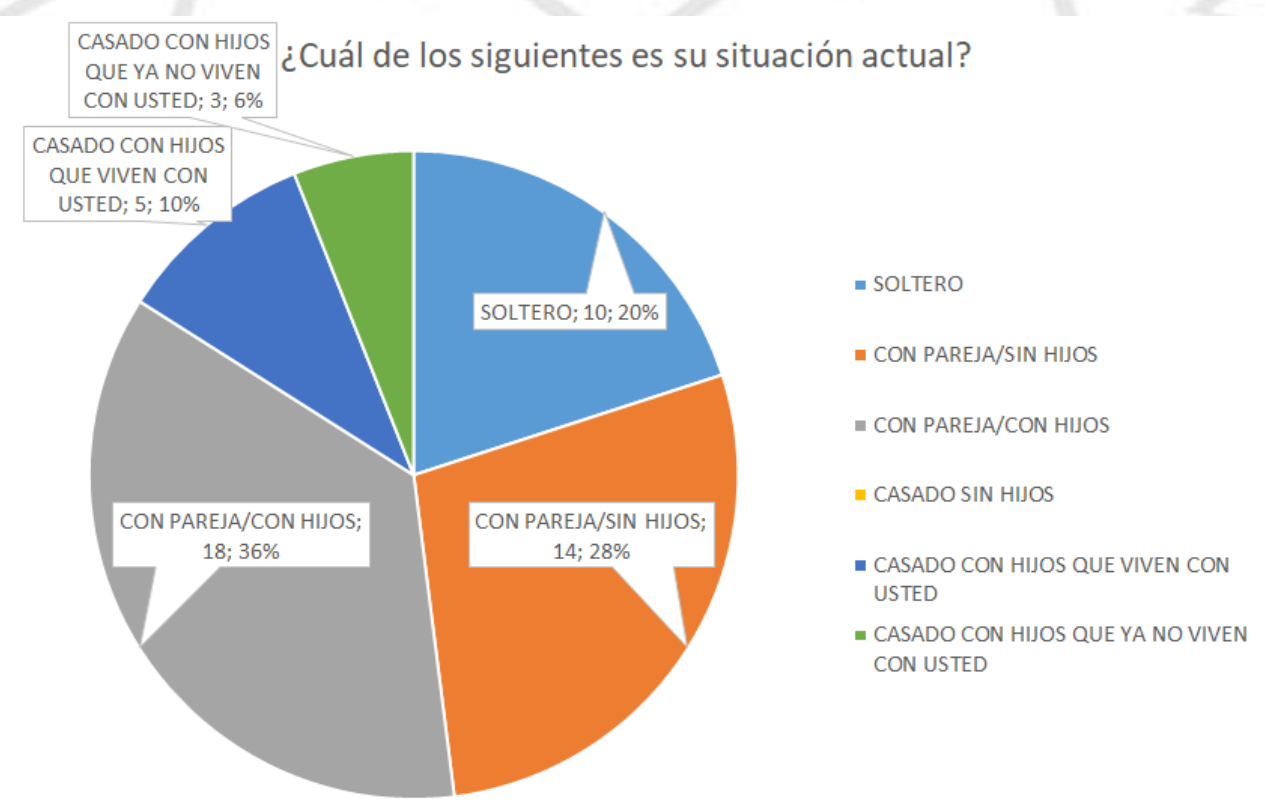

Figura 6. Encuestas a ciudadanos del distrito de Villa El Salvador. Fuente: Propia 
Pregunta 5: 45\% se informa sobre venta de departamentos a través de la televisión; $37 \%$ a través de Internet; $13 \%$ por revistas u boca a boca; y $5 \%$ radio

¿Qué medio usa para informarse acerca de la venta de departamentos?

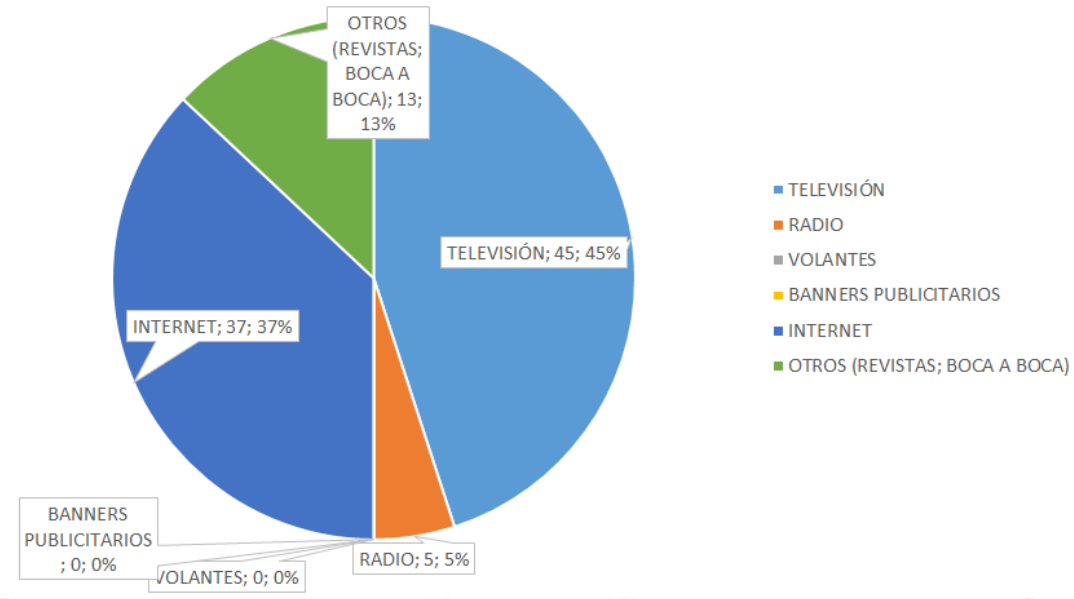

Figura 7. Encuestas a ciudadanos del distrito de Villa El Salvador. Fuente: Propia

Pregunta 6: El 78\% (39 personas) no sabía que la Villa Panamericana estaría en venta próximamente

Pregunta 7: El 100\% (50 personas) no ha recibido información acerca de la venta de los departamentos de la Villa Panamericana

Pregunta 8: Como la pregunta 7 fue que "NO", esta pregunta no llegó a contestarse Pregunta 9: El 54\% (27 personas) sí ha escuchado sobre crédito MiVivienda

Pregunta 10: El 76\% (38 personas) estaría interesado en adquirir un departamento de la Villa Panamericana, después de explicarle sobre el tema del precio, metraje, distribución del departamento y áreas comunes

Pregunta 11: El 88\% (44 personas) sí considera que el gimnasio, pista atlética, áreas de esparcimiento, etc, son una motivación importante a la hora de comprar un departamento en un condominio

Pregunta 12: Dentro de la importancia en atributos a la hora de comprar un departamento (calificación desde Sin Importancia hasta Muy Importante) encontramos que los que consideran más importantes son la Ubicación, Metraje, Espacios Comunes y Reputación de la constructora; mientras que las menos importantes son la Cantidad de Pisos y la Antigüedad. La distribución interior del departamento lo consideran de importancia promedio. 


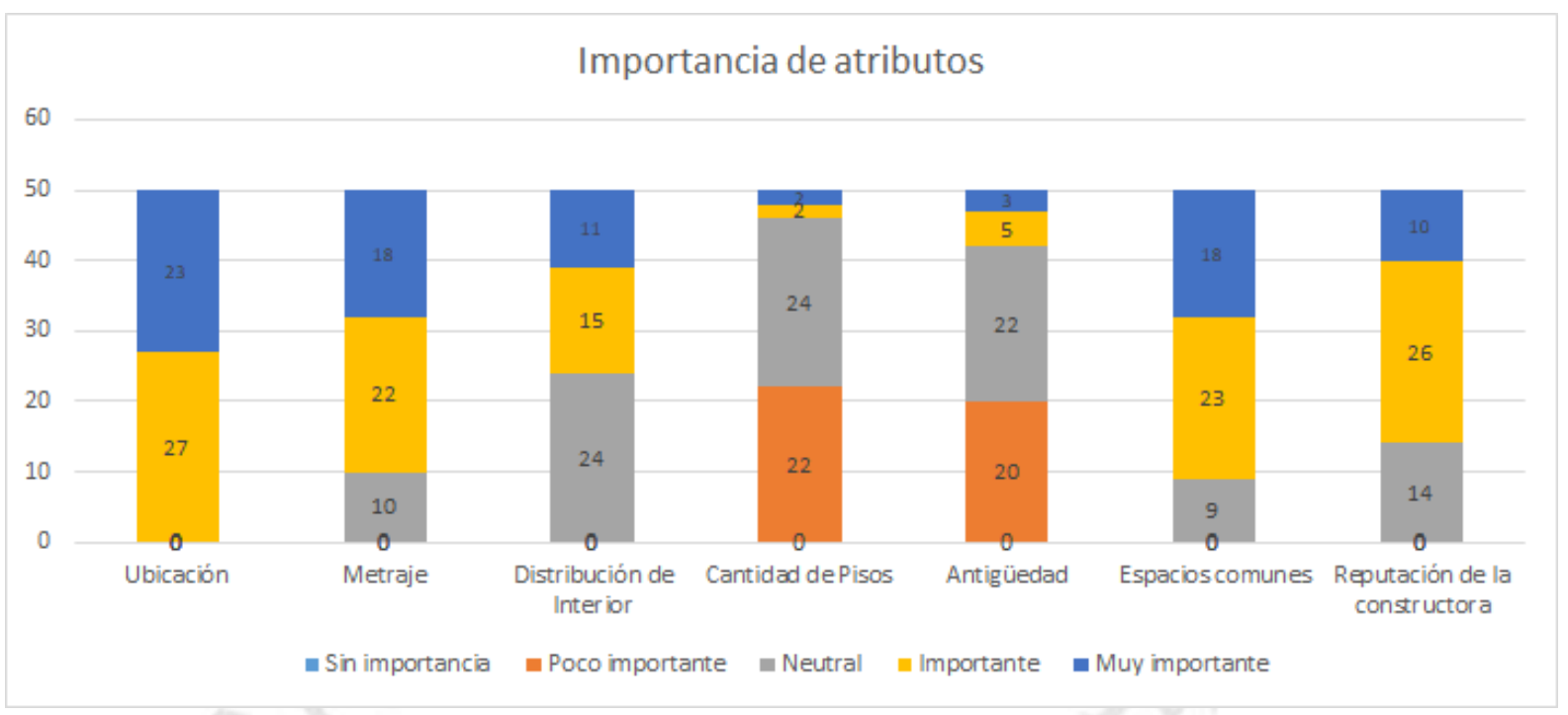

Figura 8. Encuestas a ciudadanos del distrito de Villa El Salvador. Fuente: Propia

Pregunta 13: El 82\% (41 personas) consideran que los más interesados a comprar estos departamentos serían los de Villa El Salvador y distritos aledaños como Villa María del Triunfo y San Juan de Miraflores

Pregunta 14: El 100\% no ha visto otro condominio de este tipo en el distrito

Pregunta 15: El 70\% (35 personas) sí estaría dispuesta a comprar un departamento que tenga instalaciones acondicionadas a personas con discapacidad (mismo metraje; pequeños agregados como barras de apoyo y marcos de puerta más anchos; estar en los primeros pisos de los edificios).

Pregunta 16: El 80\% (40 personas) podría reconsiderar comprar uno de los 321 departamentos diseñados para personas con discapacidad si es que fuesen los únicos disponibles de toda la Villa Panamericana. Este dato combinado con el de la pregunta 15 son importantes para el caso, debido a que pensamos de antemano que no habría alto nivel de aceptación en adquirir este tipo de departamento acondicionado, pero los datos obtenidos nos demostraron lo contrario (de esta manera no nos tenemos que limitar a vender este tipo de departamento solo a personas con discapacidad) 
Encuestas a personas que vivan en los departamentos de los condominios Los Parques de Villa El Salvador 1 y 2 :

Pregunta 1: 52\% (21 personas) tienen una edad entre los 25 a 35 años

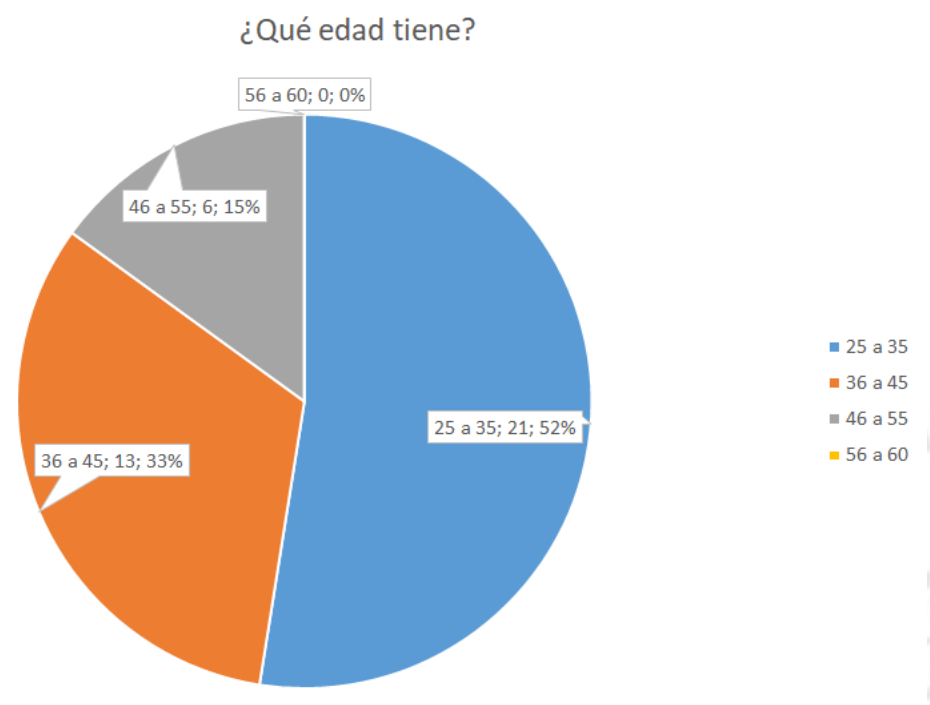

Figura 9. Encuestas a personas que vivan en los departamentos de los condominios Los Parques de Villa El Salvador 1 y 2. Fuente: Propia

Pregunta 2: El 85\% (34 personas) tiene viviendo de 4 a 6 años en el condominio Pregunta 3: De los 40 encuestados: 16 (40\%) ya vivía en Villa El Salvador antes de mudarse al condominio; 12 (30\%) vivía en Villa María del Triunfo; 9 (22\%) vivía en San Juan de Miraflores; y solo 3 (8\%) en Otros distritos

Pregunta 4: 45\% (18 personas) tiene pareja e hijos; 30\% (12 personas) es casado con hijos que aún viven con ellos; 25\% (10 personas) tiene pareja, pero sin hijos. 
Pregunta 5: 30\% (24 personas) se informó acerca de la venta de estos departamentos a través de Banners publicitarios

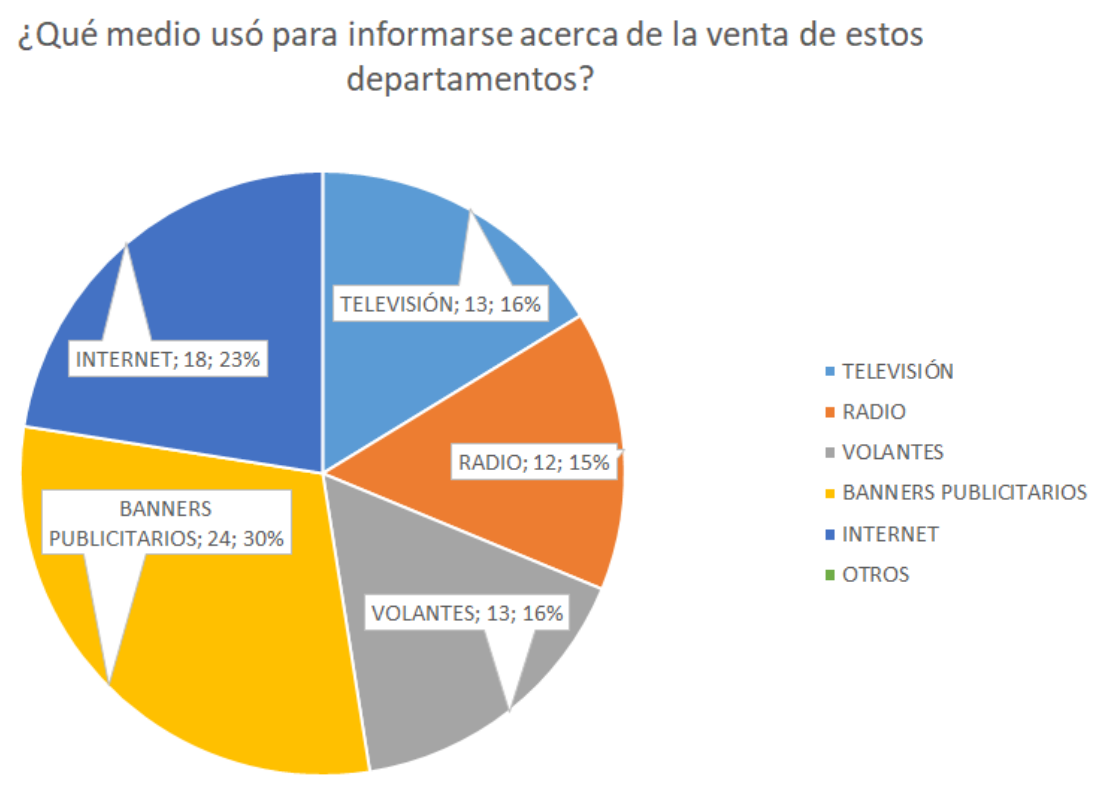

Figura 10. Encuestas a personas que vivan en los departamentos de los condominios Los Parques de Villa El Salvador 1 y 2. Fuente: Propia

Pregunta 6: $52 \%$ (21 personas) pagaron entre 121 mil a 140 mil soles; y $48 \%$ (19 personas) pagaron entre 141 mil a 160 mil soles)

Pregunta 7:55\% (22 personas) tiene departamentos de entre 51 a 60 metros cuadrados; $45 \%$ (18 personas) tiene entre 61 a 70 metros cuadrados

Pregunta 8: El 100\% (40 personas) tiene 3 dormitorios en sus departamentos Pregunta 9: El 100\% (40 personas) tienen un solo baño

Pregunta 10: 68\% (27 personas) no cuenta con estacionamiento; y el 32\% (13 personas) solo tiene 1 estacionamiento

Pregunta 11: El 100\% (40 personas) tiene un costo de mantenimiento mensual de 100 a 200 soles

Pregunta 12: El 100\% (40 personas) indicó que aparte del departamento, el condominio ofrece áreas verdes y sala de eventos (Club House) como áreas comunes

Pregunta 13: 68\% (27 personas) no considera que estos espacios comunes sean motivo por el cual compraron su departamento dentro del condominio 
Pregunta 14: 78\% (31 personas) considera estar satisfecho con el departamento adquirido; $22 \%$ (9 personas) considera estar poco satisfecho con el departamento adquirido

Entrevista telefónica a miembro del CONADIS:

El viernes 13 de setiembre nos comunicamos telefónicamente con una representante del CONADIS. Dentro de lo conversado, lo más importante sería lo siguiente:

- En la actualidad, el rubro inmobiliario está enfocado en tener espacios menos amplios y en aprovechar el construir hacia arriba lo más posible

- No tenían información alguna sobre la próxima venta de los departamentos de la Villa Panamericana

- En marzo de este año se realizó una modificación a la Norma Técnica A.120 "Accesibilidad Universal en Edificaciones", la cual busca que las obras de edificación cuenten con instalaciones adecuadas para personas con discapacidad y/o adultos mayores

- Aunque es cierto que la Norma A.120 ya se encuentra en vigencia, aún en algunos distritos no se cumple en su totalidad, debido a una fiscalización no tan minuciosa como debería ser

- La Villa Panamericana es la primera y única edificación que ha sido edificada con departamentos y áreas interiores del condominio $100 \%$ inclusivos (cumpliendo toda la normativa A.120)

- A pesar que la edificación $100 \%$ inclusiva es un gran motivador para la compra del mismo, otro gran factor que podría ser aún más importante es la ubicación del mismo, debido a que cualquier persona que se mudase quiere vivir cerca de su trabajo o familia y no alejarse más aún de ello. 


\section{LA MARCA}

\subsection{Posicionamiento}

Para lograr posicionamiento, nos enfocamos en la diferenciación que tiene la Villa Panamericana con respecto a la competencia. Esta es que se construyó dentro del marco de los Juegos Panamericanos. Además, sus instalaciones están acondicionadas para un estilo de vida ligado al deporte. También considera a un nicho completamente desatendido en el mercado peruano: personas con discapacidad.

La Villa Panamericana tiene instalaciones de primer nivel que no son habituales en el distrito, ni para los precios asignados al producto. Por lo tanto, estaríamos volviendo accesible un producto que puede ser hasta aspiracional al target.

Con respecto a la competencia en el distrito, no hay ningún condominio con estas características, lo cual también es un beneficio (condominio con instalaciones orientadas a personas con discapacidad)

En conclusión, estaríamos usando una estrategia de posicionamiento basada en los atributos.

\subsection{Promesa}

Tras la investigación realizada en el perfil del consumidor, podemos resumir el perfil de nuestro público objetivo primario como:

"Adulto joven de 25 a 35 años del NSE C y D que resida en la zona Sur de Lima y se encuentre vinculado sentimentalmente con otra persona (en proceso o ya con familia), el cual ahorra un porcentaje importante de su ingreso mensual para la compra de una vivienda propia."

A partir de esta descripción del público objetivo, nuestra promesa de marca y posicionamiento se conecta en dos puntos clave:

- Precio: se sabe que el condominio Villa del Atleta está ofreciendo un precio acorde al mercado en Villa El Salvador. (Nota: En la encuesta realizada a ciudadanos de Villa El Salvador, el 76\% sí estaría interesado en adquirir un departamento de la Villa Panamericana, después de explicarle sobre el tema del precio, metraje, distribución del 
departamento y áreas comunes). Según Ipsos, sabemos que los ingresos mensuales del público objetivo son afines a las cuotas mensuales del Fondo Mivivienda.

- Aspiracional: según las encuestas hemos encontrado que el público objetivo sí encuentra los atributos extras del condominio como un factor importante en la decisión de compra de un departamento. Nuestras instalaciones cumplen estándares internacionales que pueden equipararse a un Condominio Premium, lo que significaría mejorar considerablemente a la calidad de vida de nuestro target (un deseo aspiracional). En consecuencia, nuestra estrategia de posicionamiento está basada en atributos, que además nos diferencia con la competencia de la zona.

Una vez definidos todos estos puntos, elaboramos la siguiente promesa de marca que consideramos acorde para el proyecto:

“Ofrecer los mejores departamentos con instalaciones Premium en la Zona Sur de Lima a un precio accesible para los ciudadanos que deseen cumplir el sueño del hogar propio mejorando la calidad de vida de sus familias."

\subsection{Ventaja diferencial}

Las instalaciones y las áreas comunes son de alta calidad y no son habituales en el distrito. No hay un competidor con las características mencionadas anteriormente.

\subsection{Reason why}

- Departamentos inclusivos

- Áreas comunes ligadas al deporte de alta calidad

- Bono verde

- Fondo Mi vivienda

- Estacionamientos subterráneos

\subsection{Tono de comunicación}

El tono de comunicación es cercano, dinámico y emotivo. 


\subsection{Misión y visión de marca}

\section{Misión:}

Brindar calidad de vida a los residentes con instalaciones de primer nivel a un precio accesible.

\section{Visión:}

Ser un referente en el rubro de condominios ubicados en Villa el Salvador, ofreciendo áreas comunes e instalaciones de primer nivel ligados a la vida deportiva. 


\section{IMAGEN DE MARCA}

\subsection{Nombre}

Condominio Villa del Atleta

5.2. Logo

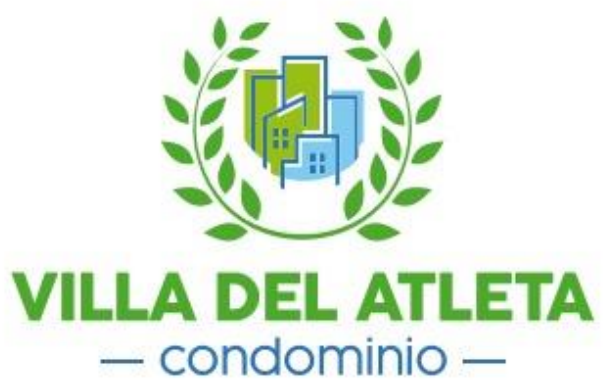

COLORES CMYK - imprenta

C: 75 M: 0 Y: $100 \mathbf{K}: 0$

C: $50 \mathbf{M}: 0 \mathbf{Y}: 100 \mathrm{~K}: 0$

C: 85 M: 50 Y: 0 K: 0

C: 55 M: 0Y: 1 K: 0

COLORES RGB - digital

R: 112 G: 168 B: 59

R: 163 G: 189 B: 49

R: 74 G: 114 B: 178

R: 152 G: 201 B: 237

Imagen 8. Manual de marca. Fuente: propia

\section{Justificación del Logo:}

Isotipo:

- Se puede apreciar el uso de 5 torres dibujadas, las cuales representan las torres de departamentos que posee el condominio

- El uso de la corona de laurel que rodea las torres tiene un doble significado:

1er: Históricamente simboliza victoria, gloria, condecoración y reconocimiento; y su origen está ligado a los tiempos antiguos de romanos y griegos, en donde la utilizaban como símbolo de victoria o 
condecoración bélica. Por ello podemos decir que es un símbolo más popular y más fácil de asociar a lo deportivo y al triunfo

- 2do: En el Perú se hace entrega de los Laureles Deportivos, que son la máxima condecoración honorífica que el país confiere a los peruanos que se hayan distinguido de manera excepcional en el ámbito deportivo. El Presidente de la Nación hace entrega de una medalla de reconocimiento, un diploma de reconocimiento, y la inscripción del nombre de la persona en un lugar designado por el presidente del IPD (Instituto Peruano del Deporte) (Comúnmente se realiza alrededor de la fachada del José Díaz/Estadio Nacional del Perú). Dentro de sus exponentes más reconocidos por la mayoría de los peruanos encontramos: Teófilo Cubillas, las voleibolistas ganadoras de medalla de plata en Seúl 1988, Sofía Mulanovich, Luis Horna, Kina Malpartida.

\section{Tipografía:}

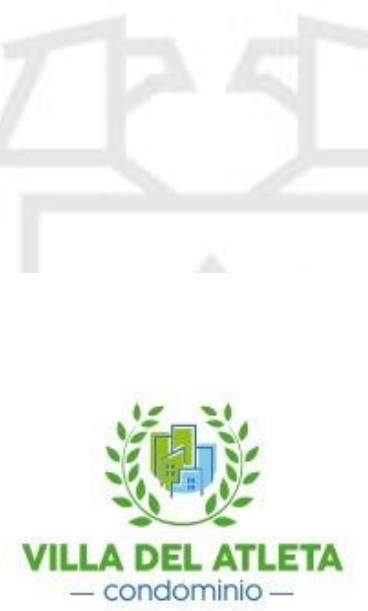

\section{ABCDEFGHICKLMNOPORSTUVWXYZ abcdefghigkImnopqrstuvwXyz}

(Cocogoose Pro)

Imagen 9. Manual de marca. Fuente: propia

- Se utiliza Cocogoose Pro como tipografía para la marca ("VILLA DEL ATLETA") como para el descriptor (-condominio-). La font permite una fácil lectura. Este tipo de letra es de aspecto fuerte y modernista, el cual ha sido suavizado mediante esquinas redondeadas y pequeñas correcciones visuales (más legible y con una altura generosa). 
Colores: (UNAYTA, 2018)

- El logotipo posee 4 diferentes colores corporativos, pero son derivaciones del color azul y el verde

- Los colores que derivan del azul (2 de 4) evocan reposo, frescura y calma, lo cual es lo que finalmente buscan las personas al buscar un hogar

- Los colores que derivan del verde (2 de 4) están directamente relacionados con la naturaleza y vegetación (en este caso aprovechamos el Bono Verde que tiene el condominio por ser ecoamigable). También tiene un efecto de dar tranquilidad y ser sedante, por lo que se crea un equilibrio en la combinación de los colores usados

\section{Logos no llegados a usar:}

Los siguientes logos que mostraremos fueron elaborados mediante el uso de los colores representativos del logo oficial de los Juegos Panamericanos Lima 2019. Decidimos que finalmente no serían utilizados, porque visualmente la paleta de colores está recargada y no llega a transmitir el sentimiento de calma y al mismo tiempo funcional que deseamos.

- $\quad$ Logo oficial de Lima 2019:

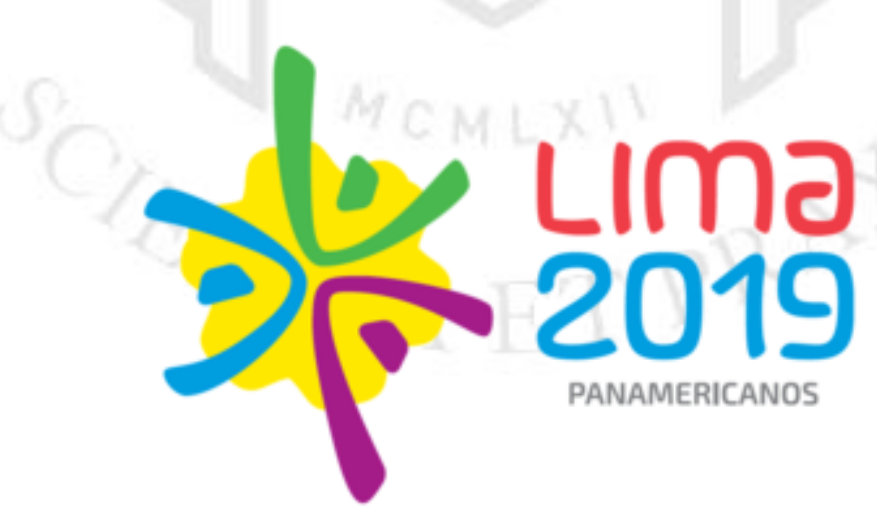

Imagen 10. Logo Juegos Panamericanos. Fuente: Lima 2019 
- Logos propios con paleta de colores de Lima 2019 Opción 1:

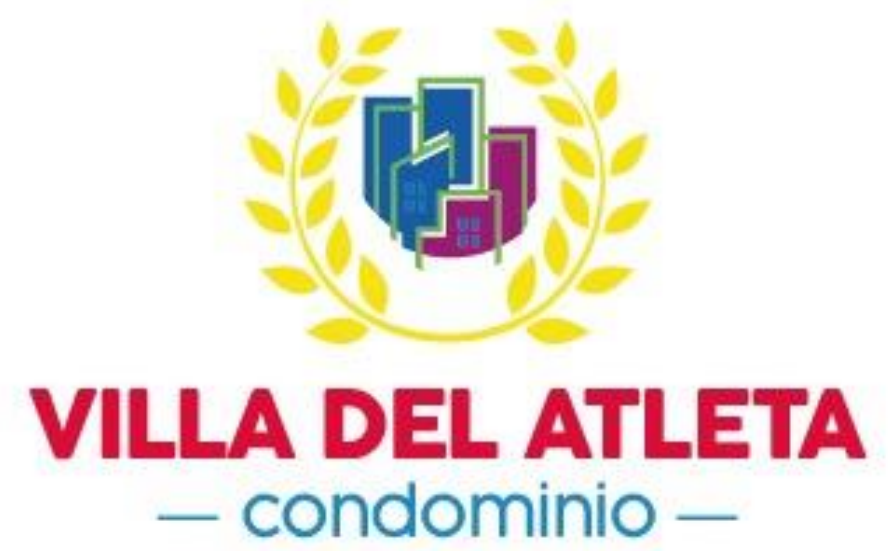

Imagen 11. Logo Villa del Atleta modificado 1. Fuente: propia

Opción 2:

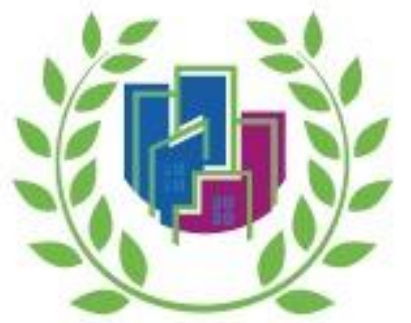

\section{VILLA DEL ATLETA}

- condominio -

Imagen 12. Logo Villa del Atleta modificado 2. Fuente: propia 
Opción 3:

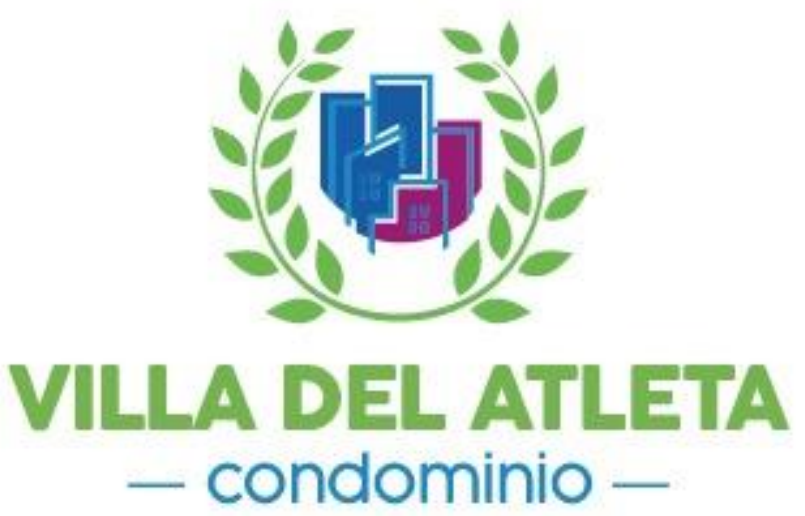

Imagen 13. Logo Villa del Atleta modificado 3. Fuente: propia

\subsection{Manual de marca}

El manual de marca se ha adjuntado en el link del repositorio digital mencionado en las primeras páginas. 


\section{LA CAMPAÑA}

\subsection{Objetivos}

\subsubsection{De marketing}

Lograr la venta del $100 \%$ de los departamentos en un lapso de 6 meses (se iniciará 2020 terminando Julio)

\subsubsection{De comunicación}

- Generar awareness del proyecto y sus atributos con un adecuado mix de medios

- Posicionarnos como el mejor Condominio de la Zona Sur de Lima, siendo las instalaciones Premium nuestro principal atributo.

- Generar intención de compra en el público objetivo usando como razón principal el precio

- Comunicar las facilidades de financiamiento a través del crédito Mivivienda

\subsection{Estrategia creativa}

\subsubsection{Concepto}

Concepto: Vive como un campeón

La comunicación se basa en los atributos del proyecto, que además son la principal diferencia frente a sus competidores: Cuenta con instalaciones de primer nivel avaladas internacionalmente (tanto los departamentos mismos como las áreas comunes), las cuales se pondrán a disposición de todos los que deseen adquirirla a un precio mucho menor de lo normal. 


\subsubsection{Idea}

\section{VIVE COMO UN CAMPEÓN:}

Los deportistas peruanos que obtuvieron una medalla son considerados los Mejores Deportistas del Continente Americano, y por ello se les recompensa con un departamento considerado al mismo nivel continental.

Nuestra idea de "Vive como un Campeón" tiene dos énfasis en los que nos centramos y que están relacionados. En primer lugar, es la suma del orgullo como nación y respeto a los ojos del continente, todo ello reflejado en el Condominio Villa del Atleta, una instalación de primer nivel que será puesta a venta a cualquier ciudadano que desee adquirirla.

Así, la idea creativa propone a la Villa del atleta como un legado y premio al esfuerzo no solo de los deportistas, sino de todos los peruanos. Todos merecen un condominio de primer nivel y vivir como un campeón.

En segundo lugar, queremos que la idea evoque en el comprador el sentimiento de realización personal, ya que solo se "puede ser un campeón" mediante el esfuerzo diario y dedicación en búsqueda del objetivo (en este caso dar una mejor calidad de vida para sí mismo y su familia). Poder adquirir un departamento en el Condominio Villa del Atleta sería la suma de todo ello en algo tangible. 


\subsection{Estrategia de medios}

El lanzamiento de este producto será en Enero del 2020 y se contará con 6 meses para lograr la venta de todos los departamentos. Por ello consideramos estar activos con la pauta los 6 meses. La propuesta es partir la comunicación en 2 etapas: 3 meses de Lanzamiento y 3 meses de Mantenimiento.

\begin{tabular}{|l|l|l|}
\hline ETAPA & Lanzamiento & Mantenimiento \\
\hline OBJETIVO & $\begin{array}{l}\text { Generar awareness del } \\
\text { producto y concepto de } \\
\text { campaña. }\end{array}$ & Recordación de marca \\
\hline DESCRIPCIÓN & $\begin{array}{l}\text { Se trabajará el mejor mix } \\
\text { de medios para lograr la } \\
\text { cobertura necesaria en } \\
\text { Lima con el mejor costo }\end{array}$ & $\begin{array}{l}\text { Mantener la presencia de } \\
\text { marca para generar } \\
\text { venta }\end{array}$ \\
\hline MEDIOS & $\begin{array}{l}\text {-Radio } \\
\text {-OOH asegurar la } \\
\text {-Digital } \\
\text {-Prensa } \\
\text {-Evento de Lanzamiento }\end{array}$ & -Digital \\
\hline
\end{tabular}

En cuanto a nuestra propuesta de comunicación basada en dos etapas:

- En la etapa de lanzamiento no tocamos en profundidad el tema de la familia, debido a que nuestro foco de comunicación busca resaltar los atributos más importantes que nos distinguen de la competencia. Estos atributos son los que realzan la idea de "Vive como un campeón".

Hemos decidido que para la etapa de mantenimiento vamos a destacar el componente familiar, sin desligarnos de la idea de Vive como un campéon, el cual se verá reflejado en la ejecución gráfica. El mensaje que queremos comunicar es: "Tu familia merece lo mejor. Vive como un Campeón" 


\section{Ecosistema de Medios:}

\begin{tabular}{|l|c|c|}
\hline \multicolumn{1}{|c|}{ Mix de medios } & Penetración (\%) & Afinidad (Aff.) \\
\hline Internet & $85 \%$ & 112 \\
\hline Diarios & $62 \%$ & 104 \\
\hline Radio & $62 \%$ & 103 \\
\hline Vía Pública & $85 \%$ & 102 \\
\hline TV Abierta & $82 \%$ & 99 \\
\hline Cine & $36 \%$ & 92 \\
\hline Cable & $53 \%$ & 88 \\
\hline Revista & $5 \%$ & 53 \\
\hline
\end{tabular}

Figura 11. Afinidad de medios HYM Lima 25 a 35 CDE. Fuente: TGI,2019

\begin{tabular}{|l|c|c|}
\hline \multicolumn{1}{|c|}{ Mix de medios } & Penetración (\%) & Afinidad (Aff.) \\
\hline Radio & $64 \%$ & 107 \\
\hline TV Abierta & $88 \%$ & 106 \\
\hline Diarios & $62 \%$ & 105 \\
\hline Vía Pública & $86 \%$ & 103 \\
\hline Internet & $64 \%$ & 84 \\
\hline Cable & $49 \%$ & 82 \\
\hline Revista & $6 \%$ & 65 \\
\hline Cine & $24 \%$ & 62 \\
\hline
\end{tabular}

Figura 12. Afinidad de medios HYM Lima 35 a 55 CDE. Fuente: TGI,2019

Según TGI, observamos que para nuestro primer público objetivo, los medios con mayor afinidad son Internet, Diarios, Radio y Vía Pública. Por otro lado, para el público objetivo más adulto, el Internet pasa a un segundo plano, y es la TV Abierta la que sustituye como medio con mejor afinidad. Sin embargo, hemos optado por no usar TV por una optimización de costos y porque no necesitamos una comunicación tan masiva debido a que el proyecto y la venta está concentrada solo en Lima.

Estaríamos aprovechando los canales digitales para poder dar cobertura a nuestro material audiovisual (spot), debido a que los costos son mucho menores y por la posibilidad de tener una segmentación geolocalizada. 
Finalmente, nuestro mix de medios final incluiría:

-Radio

-Prensa

$-\mathrm{OOH}$

-Digital

$-P R$

$-B T L$

\subsubsection{Etapa de Lanzamiento}

\subsubsection{Radio}

Tendremos presencia en radio con un spot de 20 segundos. Hemos elegido dos radios presentes en Lima considerando la afinidad con el target y también por el mejor costo CPM. También tendremos presencia en una radio local que nos permite tener una cobertura más geolocalizada. La Pauta estará activa de lunes a viernes, porque son los días en los que hay más audioescuchas.

- Nueva Q FM

- Radiomar FM

- Stereo Villa : Cobertura (San Juan de Miraflores, Villa El Salvador, Villa María Del Triunfo, Chorrillos y Lurín ) 


\begin{tabular}{|c|c|c|c|c|c|c|c|}
\hline & C.P & ENCIA RADIA & AL DE EMISO & RAS (FM/AN & & & \\
\hline Tipo d & de salida & Miles( G.O. o & de Referencia & : HMTotal/C/ & (DE) & & \\
\hline Ciuda & & Lima Metrop & oolitana & & & & \\
\hline Period & & Mayo 2019 & & & & & \\
\hline Lugar & de Audiencia & Global & & & & & \\
\hline Bloque & Ie Dias & Lun-Dom & & & & & \\
\hline Bloque & le Horario & $06: 00-21: 59$ & & & & & \\
\hline Grupo & objetivo & [Bajo Superic & or] [HombresI & Mujeres $/ 25-5$ & & & \\
\hline Zona & & Norte/Este/C & Cen.l/Cen.II/O & Deste/Sur & & & \\
\hline Univer & erso & 1195.8 & & & & & \\
\hline Muest & tra & 331 & & & & & \\
\hline Rnkg & Emisora & Rtg & Mls & Adhesión & Afinidad & & CPM \\
\hline & Audiencia Promedio & 20.7 & 247.6 & & & $20^{\prime \prime}$ & \\
\hline 1 & Nueva Q Fm (FM) & 1.7 & 19.9 & 26.0 & 188 & $S / 150.86$ & $S / 7.58$ \\
\hline 2 & R.P.P. (FM/AM) & 1.5 & 17.8 & 13.9 & 100 & $S / 336.60$ & $S / 18.91$ \\
\hline 3 & Radiomar (FM) & 1.3 & 15.5 & 29.0 & 216 & $S / 134.00$ & $S / 8.65$ \\
\hline 4 & La Karibeña (FM) & 1.2 & 14.5 & 18.4 & 133 & $S / 170.00$ & $S / 11.72$ \\
\hline 5 & Moda $(F M)$ & 1.2 & 14.2 & 13.1 & 92 & $\mathrm{~S} / 235.00$ & $S / 16.55$ \\
\hline 6 & Exitosa (FM) & 1.1 & 13.3 & 18.6 & 137 & $\mathrm{~S} / 400.00$ & $S / 30.08$ \\
\hline
\end{tabular}

Figura 13. C.P.I. AUDIENCIA RADIAL DE EMISORAS (FM/AM). Fuente: CPI,2019

\section{Guión spot radial:}

Como imagen del spot radial hemos escogido a dos deportistas: Christian Pacheco (Medallista de Oro en maratón Lima 2019) y María Fernanda Reyes (Medallista de Plata en Surf-Longboard).

Guion:

- Atleta olímpico: Hola, soy Christian Pacheco, medallista de oro en Lima 2019. El camino nunca es fácil, pero la recompensa es eterna. Hemos hecho historia y la muestra de ello es el Condominio Villa del Atleta, múdate a un departamento hecho para campeones.

- Voz en off del locutor: Pide tu financiamiento a través del Fondo Mivivienda en tu banco de confianza.

- Atleta Olímpico: Múdate a la Villa del Atleta. Vive como un campeón.

- Voz en off del locutor: Infórmate en VillaDelAtleta.com y llámanos al 0800-12200.

NOTA: Para el caso del María Fernanda, sólo se cambiará la primera parte a:

- Atleta olímpico: Hola, soy María Fernanda Reyes, medallista de plata en Lima $2019(\ldots)$ 


\subsubsection{2. $\mathrm{OOH}$}

En el rubro inmobiliaria, los elementos de la Vía Pública son un medio esencial porque permiten lograr una buena cobertura en la zona de afluencia. Por ello, abarcaremos 4 puntos estratégicos comunicando el concepto creativo "Vive como un campeón".

Estos puntos estarán ubicados en Villa El Salvador (2), Villa María del Triunfo (1) y en San Juan de Miraflores (1).

Christian Pacheco y María Fernanda Reyes serán la imagen de campaña en los 4 paneles escogidos. Cada uno tendrá uno en Villa El Salvador; en el de Villa María del Triunfo estará María Fernanda Reyes (ella vive en ese distrito); y en el de San Juan de Miraflores estará Christian Pacheco.

\begin{tabular}{|l|c|c|c|}
\hline \multicolumn{1}{|c|}{ ELEMENTO } & DISTRITO & DIRECCION \\
\hline TORRE UNIPOLAR & SAN JUAN DE MIRAFLORES & Panamericana Sur km. 11 \\
PANEL & VILLA EL SALVADOR & Av. Pastor Sevilla cruce con av. El Sol \\
PANEL & VILLA MARIA DEL TRIUNFO & Av. Pachacutec cruce con av. Juan Velazco \\
PANEL SEMBRADO & VILLA EL SALVADOR & Av. Atocongo / Av. Las Palmas & INVENTA KS
\end{tabular}

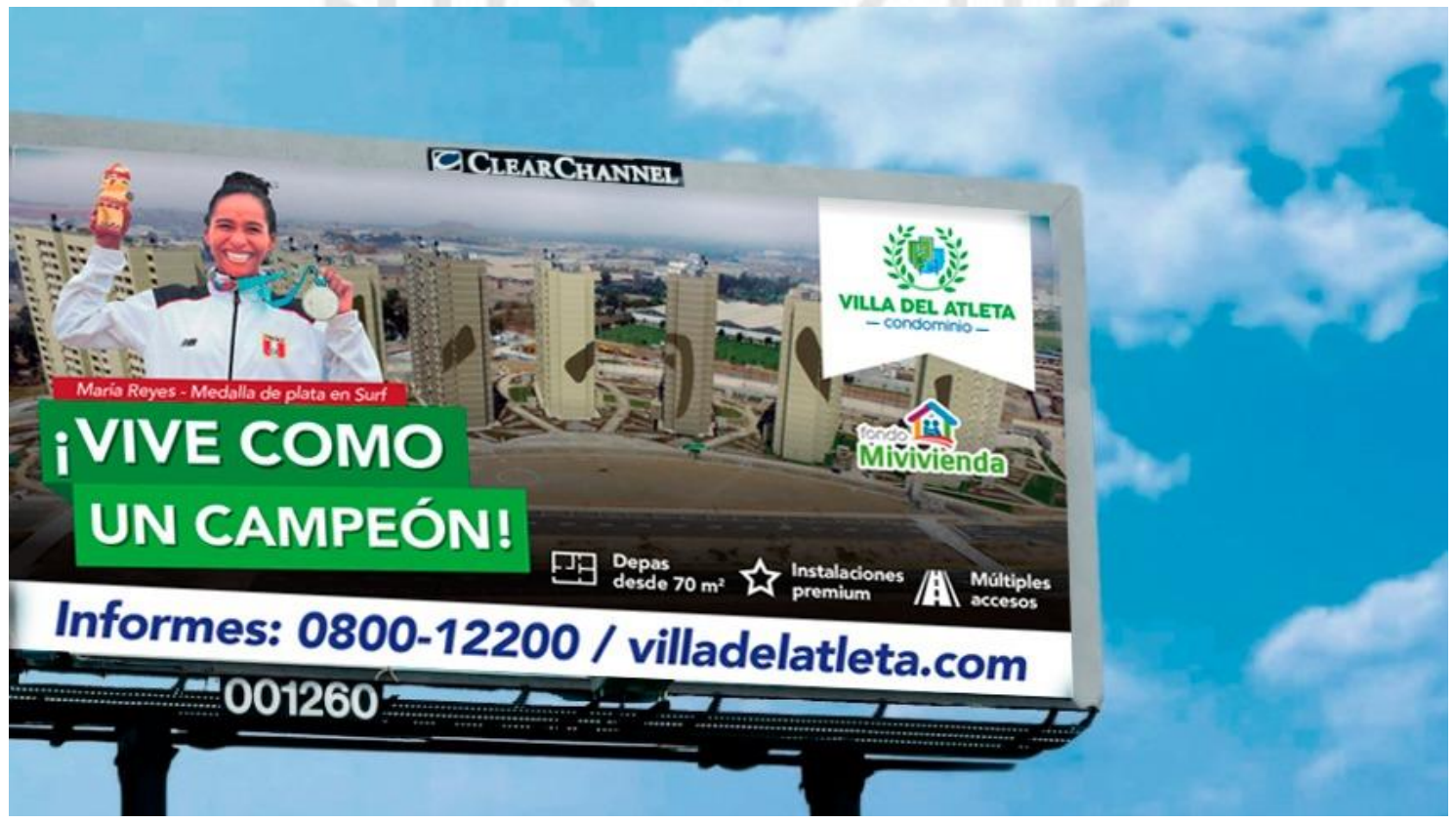

Imagen 14. Elemento de $\mathrm{OOH}$ (Etapa Lanzamiento). Fuente: propia 


\subsubsection{Prensa}

Según el nivel de lectoría en nuestro público objetivo, encontramos que Trome es el periódico con mayor consumo, por lo cual lo hemos incluido en nuestro mix de medios.

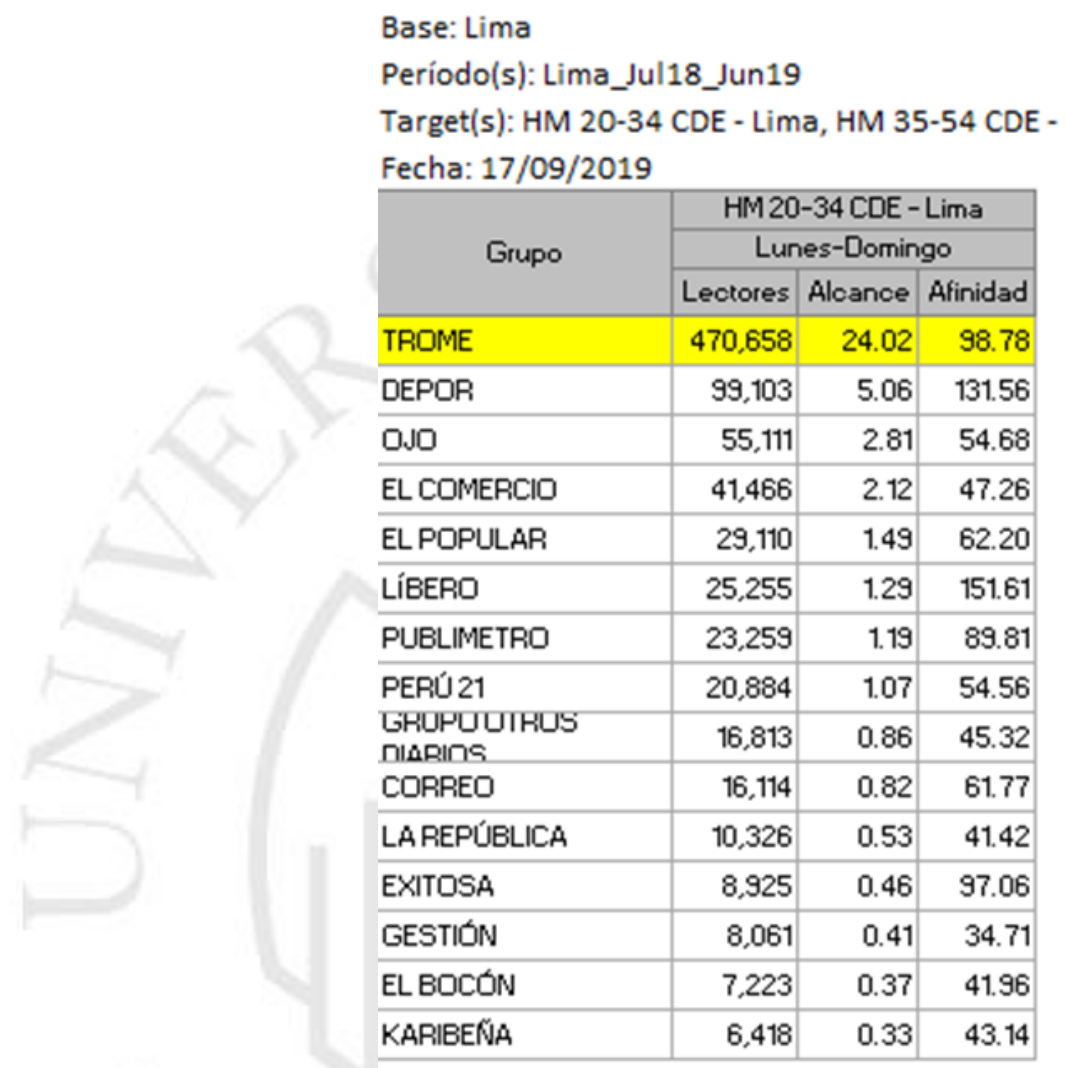

Figura 14. Afinidad de lectoría HM 20-34 CDE-Lima. Fuente: Reader Data 2019 


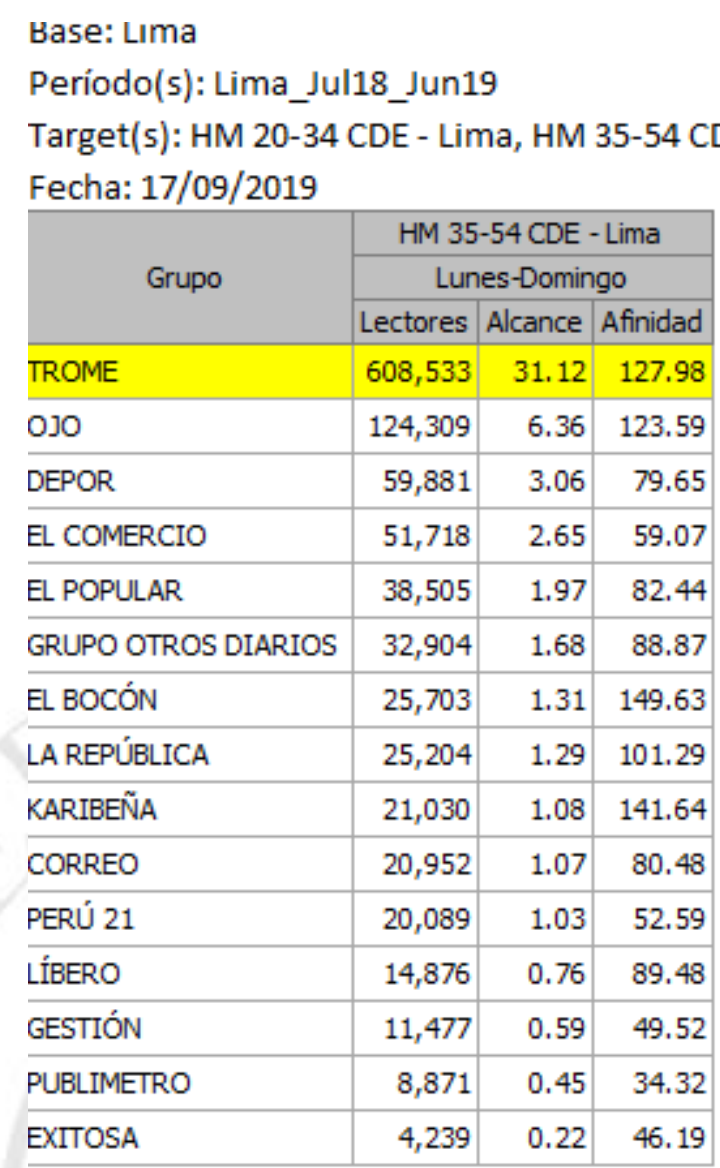

Figura 15. Afinidad de lectoría HM 35-54 CDE-Lima. Fuente: Reader Data 2019

Sin embargo, evaluamos los costos promedio de la prensa a nivel nacional y, además de ser costosa, no cumplía con nuestro objetivo de comunicación en los lugares de afluencia. Por ello, para lograr la cobertura necesaria con una buena optimización, optamos por Trome Zonal sur (Chorrillos, San Juan de Miraflores, Villa María del Triunfo y Pachamacac). La entrega de este diario es gratuita y viene de complemento los martes junto con el diario principal.

Este diario tiene un tiraje de 55,000 que es similar al tiraje de Correo nivel Lima $(50,000)$. Además, no es tan lejano a Ojo nivel Lima $(110,000)$ que está en el top 3 de nivel lectoría. Esta información fue conseguida por medio del Media Kit de cada diario.

Nuestra presencia sería por 3 meses, con una página completa en la 5ta página para contribuir así con el buzz publicitario en la etapa de Lanzamiento. 


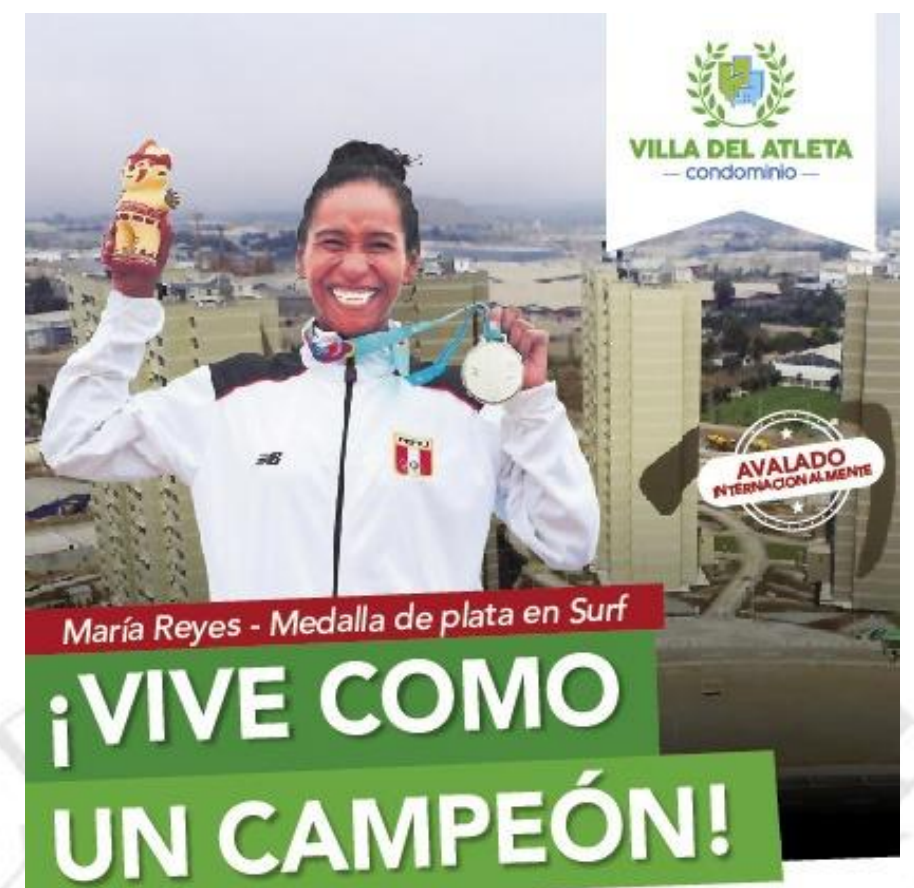

\section{Condominio ubicado en Villa El Salvador}

- Más de 1000 departamentos de estreno

- Desde 70 m2 - 3 dormitorios $/ 2$ baños

- Cochera subterránea

- $100 \%$ inclusivos"

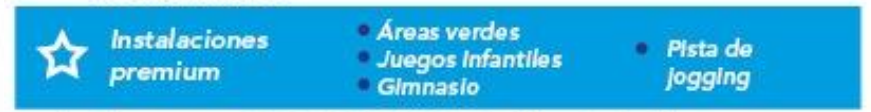

Informes: 0800-12200 / villadelatleta.com

Imagen 15. Elemento de Prensa. Fuente: propia

\subsubsection{Digital}

\section{Páqina web}

Se creará una página web cuyo link será VillaDelAtleta.com. En ella mostraremos fotos y videos del Condominio, así como información de los costos de venta. Usaremos este medio para poder informar más sobre el Fondo Mivivienda y sus beneficios. Para poder informar más al detalle sobre el Fondo Mivivienda, tendremos un enlace directo en nuestra página web ("Cotiza Aqui") que dirigirá a la persona al Simulador De Nuevo Crédito Mivivienda.

La principal función de la página web es que el usuario que la visite llene un formulario de registro, y también tenga facilidad de comunicarse con un asesor que le explicará al 
detalle sobre el mismo. Este activo digital es importante porque, impulsado con la pauta digital, logrará la cantidad de leads necesarios para alcanzar el objetivo comercial.

Se tiene pensado invertir un total de 7,000 soles en la construcción del landing.

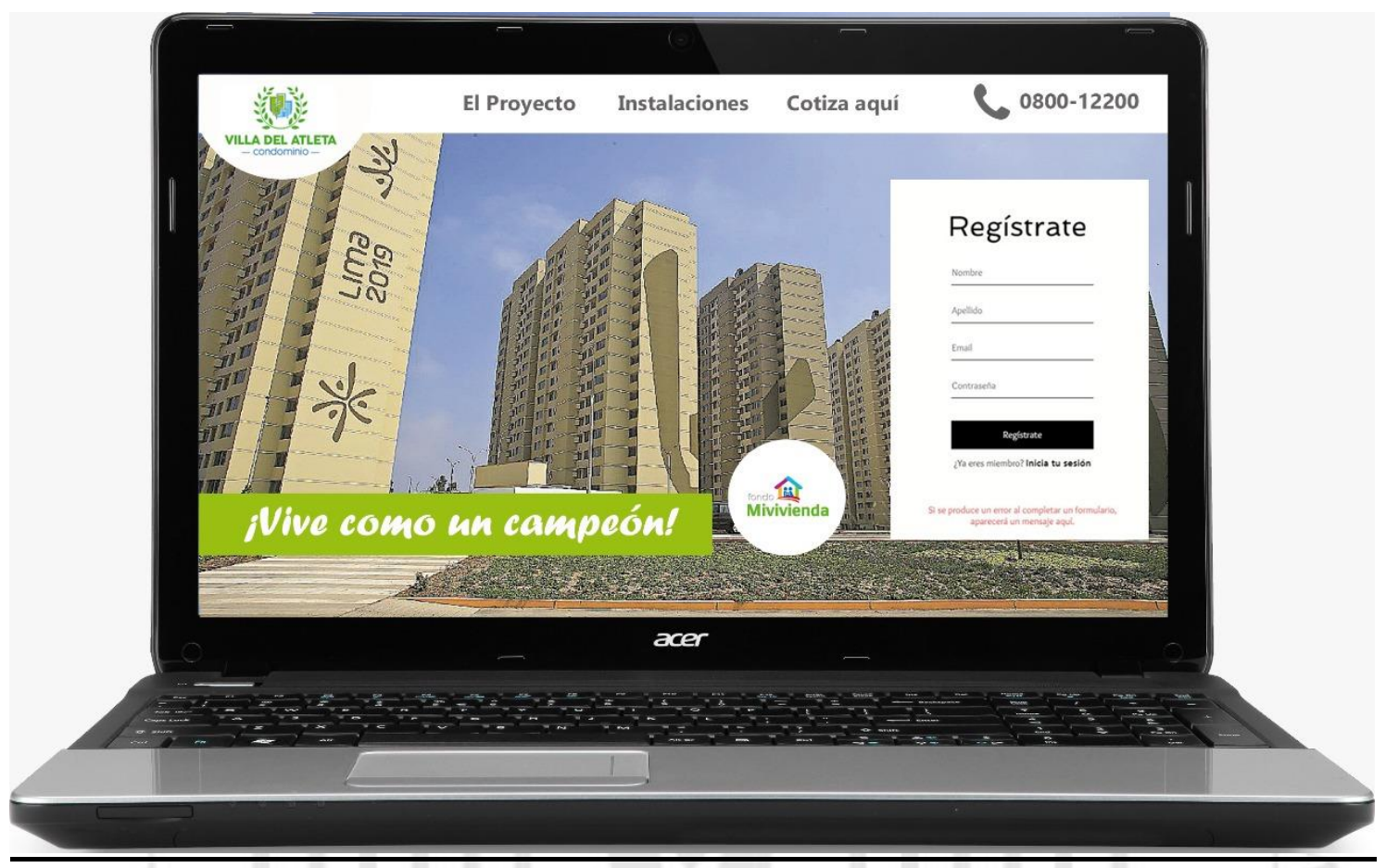

Imagen 16. Página web VillaDelAtleta.com. Fuente: Propia 


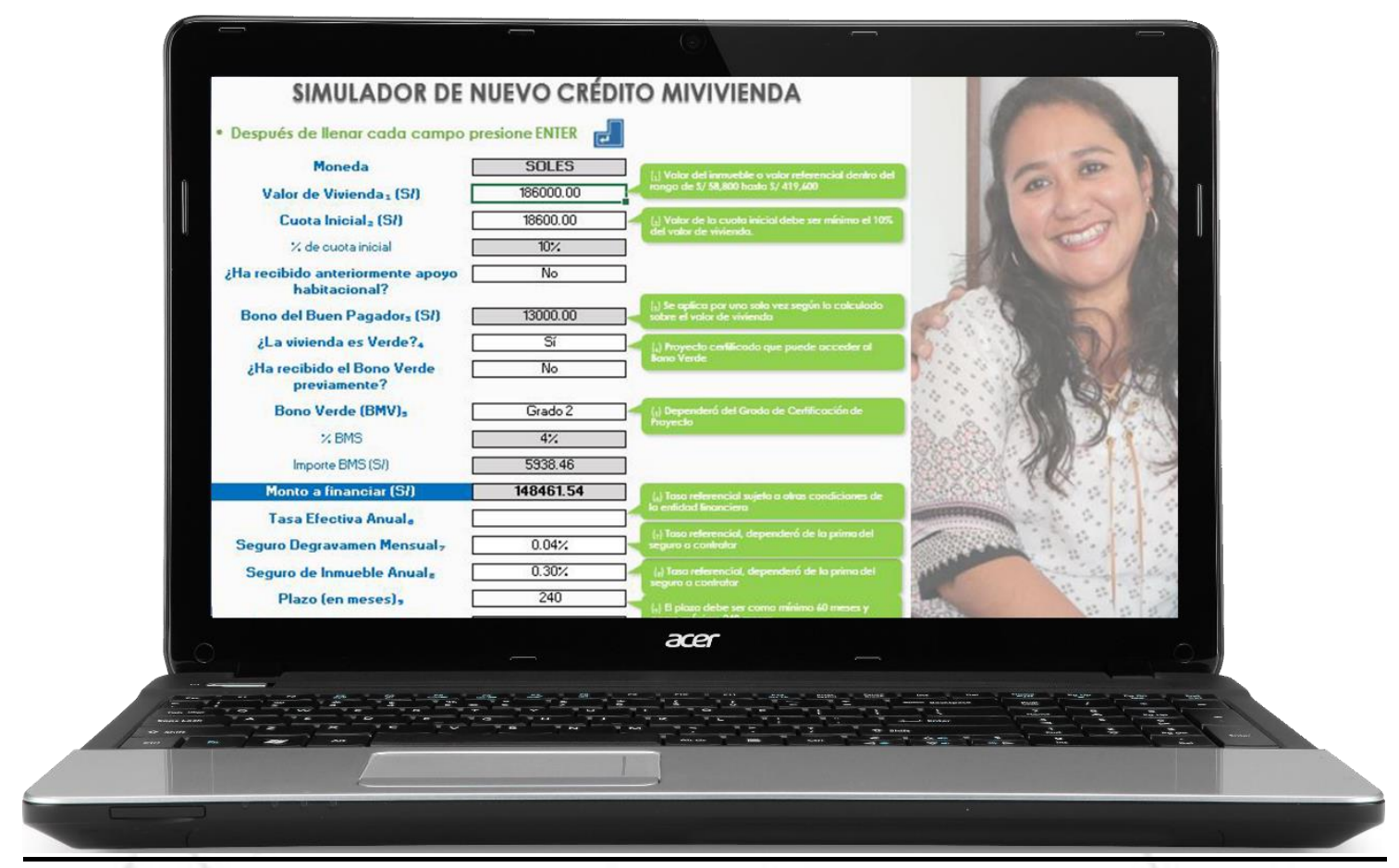

Imagen 17. Simulador de Nuevo Crédito Mivivienda. Fuente: Fondo Mivivienda

\section{Acciones digitales}

En Digital vamos a concentrar una buena parte del presupuesto (38\%), debido a la capacidad de segmentación personalizada (intereses, localización, etc). El objetivo de las acciones digitales se dividirá en tres: Branding; Awareness y Performance (Conseguir leads). A continuación, mostraremos el desglose de los canales según el objetivo:

\begin{tabular}{|l|l|l|}
\hline \multicolumn{1}{|c|}{ Awareness } & Branding & Performance \\
\hline$\bullet$ YouTube & $\bullet$ Facebook & $\bullet$ Google \\
$\bullet$ Facebook & $\bullet$ Instagram & \\
\hline
\end{tabular}




\section{YouTube}

Debido a que no tendremos spot televisión, realizaremos material audiovisual para la plataforma de YouTube. Una de las ventajas principales de este medio es que el costo es por vista. Así, la plataforma solo te cobra siempre y cuando el usuario vea el anuncio completo. Esto sumado a una buena segmentación logra excelentes resultados

*Instream: Este formato te permite tener el anuncio clásico de 30 segundos. Usaremos una gran parte del presupuesto para los 3 primeros meses, comunicando el concepto creativo: Vive como un campeón.

Estamos proyectando lograr 500,000 vistas completas de 30 segundos.

\section{Guion Video YouTube:}

El atleta Christian Pacheco fue el escogido para protagonizar el video que se transmitirá a través de YouTube. (Nota: el Storyboard se adjuntó en el repositorio digital)

Locación: Christian Pacheco sentado en una banca de un parque en Villa El Salvador

- Christian Pacheco: Hola, soy Christian Pacheco, medallista de oro en Lima 2019 (NOTA: mientras lo dice se inserta un video de cuando llega a la meta con el narrador diciendo: "Nuestro campeón, gracias por tanto")

Christian Pacheco: La vida está llena de obstáculos (el encuadre vuelve a la toma en la que está sentado en la banca del parque)

- Christian Pacheco: Ya sabemos que el camino nunca es fácil (NOTA: mientras lo dice se inserta un video de él corriendo con casaca con capucha en la madrugada en un barrio de Villa El Salvador con la imagen de las casas y el cerro de fondo)

- Christian Pacheco: , pero la recompensa es eterna. Hemos hecho historia (NOTA: mientras lo dice se inserta un video donde se le ve llorando abrazando a su familia inmediatamente después de ganar la carrera)

- Christian Pacheco: Y la muestra de ello es el Condominio Villa Del Atleta (NOTA: mientras lo dice se muestra al atleta sentado 
en una banca dentro del Condominio Villa Del Atleta con las áreas verdes, edificios y una familia entrando de fondo)

- Christian Pacheco: Múdate a la Villa del Atleta. Vive como un campeón. (NOTA: se hará un paneo del condominio mientras lo dice)

- Voz en off de locutor: Pide tu financiamiento a través del Fondo Mivivienda en tu banco de confianza. Llama al 0800-12200 y compra tu depa con el bono que te damos para completar tu cuota inicial (NOTA: mientras el locutor habla pondremos imágenes que muestran los mejores atributos del condominio y dentro de estas imágenes insertamos información de precios)

\section{Facebook}

Facebook es un medio de mucha afinidad en nuestro target, además que nos permite crear contenido de valor centrándonos de los 3 pilares de comunicación.

\begin{tabular}{|l|l|l|}
\hline Proyecto & $\begin{array}{l}\text { Facilidades de } \\
\text { Financiamiento }\end{array}$ & $\begin{array}{l}\text { Instalaciones para } \\
\text { campeones }\end{array}$ \\
\hline $\begin{array}{l}\text {-Comunicaremos los } \\
\text { atributos del proyecto } \\
\text { - Destacaremos las áreas } \\
\text { comunes }\end{array}$ & $\begin{array}{l}\text { El precio de los } \\
\text { departamentos }\end{array}$ & $\begin{array}{l}\text { Curiosidades de } \\
\text { los }\end{array}$ \\
& Fondo Mi Vivienda & $\begin{array}{l}\text { Panamericanos } \\
\text { Destacaremos las } \\
\text { curiosidades sobre } \\
\text { la construcción }\end{array}$ \\
\hline
\end{tabular}

Se usará un mix de formatos para poder lograr una correcta comunicación y para mayor dinamismo. 


\section{*Page post Video}

Usaremos el spot de YouTube, pero una versión más corta debido a que la atención en esta plataforma es más volátil. Además, el costo por vista es a los 3 segundos, por lo cual todos los motivos no excederán los 15 segundos en duración.

Se utilizarán 3 cápsulas del Video Principal de 15 segundos comunicando el concepto creativo

Se utilizarán 3 cápsulas de 10 segundos comunicando la oferta comercial

\section{*Page Post Ad}

Se usarán las fotos para comunicar, principalmente, el segundo y tercer pilar de comunicación.

- Se realizarán 10 motivos para comunicar las facilidades de financiamiento

- Se realizarán 26 motivos para comunicar Instalaciones para campeones. Todos tendrán pauta.

\section{${ }^{\star}$ Foto 360}

También usaremos motivos con fotos de 360 para mostrar el condominio en general de una forma interactiva y dinámica

\section{*GIF}

Este formato lo usaremos debido a que es dinámico y corto, además ayuda mucho para objetivos de interacción. No todos los motivos serán pauteados.

\section{*Page Post Link}

Usaremos este formato debido a que uno de nuestros principales objetivos es generar leads. Por ello, necesitamos lograr el mayor tráfico posible a nuestro landing. La segmentación será bastante fina para poder lograr un tráfico de calidad. También trabajaremos remarketing con las personas que ya han visitado nuestra página para poder generar intención de compra. Finalmente, se hará un seguimiento.

Serán 28 motivos que comunicarán el primer y segundo pilar de comunicación (información comercial). Todos estos tendrán pauta. 


\section{Instagram}

Usaremos Instagram debido a que es la tercera red social más usada por los peruanos. (EL COMERCIO, 2019)

\section{*Story}

Usaremos este formato debido a su dinamismo y al alcance que genera. Serán mensajes cortos que comunicarán el concepto de campaña y también la oferta de comercial.

\section{*PPL}

Complementaremos la comunicación con formato que puedan aportar al tráfico a la web de generación de leads.

\section{Google}

Google es uno de los medios digitales principales debido a que es el principal buscador y además por el inventario (red de sitios web) que posee.

\section{*Display}

Estaremos presentes en los principales sitios web de navegación de nuestro target. La segmentación se hará por intereses o afinidad relacionados a inmobiliaria, hogar, inversión etc. También por categorías de mercado que son personas que tienen mayor disposición a lograr una conversión. Finalmente, usaremos una estrategia de remarketing mediante el píxel de google. Así haremos seguimiento a personas que ya visitaron nuestra página, pero no lograron "convertir" (dejar su formulario)

\section{*Search}

Este medio será uno de los principales, sobre todo en esta etapa de Lanzamiento. Cubriremos todas las búsquedas de nuestro público objetivo, que estén en una etapa de consideración de compra de una inmobiliaria. 
Además, Google es el medio que posee el mejor costo por conversión. Estos son formularios de alta calidad y que están más dispuestos a cerrar una venta porque ya están en una etapa de búsqueda activa.

Las keywords a usar irán desde el producto de la marca: "Villa del atleta", "Villa Panamericana" a palabras más categóricas y genéricas como: "departamentos en Villa EI Salvador" y "departsamentos en San Juan de Miraflores", etc.

\subsubsection{Evento de Lanzamiento - Relaciones Públicas}

Se realizará un evento de lanzamiento el sábado 11 de enero. El costo será de 30 mil soles. En este evento invitaremos a los atletas que hayan conseguido medallas en Lima 2019 (Panamericanos y Parapanamericanos), y también a la prensa en general con el fin de informar sobre la venta de los departamentos del condominio y a la vez crear rebote en medios de forma rápida.

Dentro de los atletas que irán, queremos contar indispensablemente con la presencia de Gladys Tejeda (Atletismo), Christian Pacheco (Atletismo), María Fernanda Reyes (Surf) (por parte de los atletas Panamericanos); Carlos Felipa (lanzamiento de bala) y Juana Vásquez (Powerlifting) (por parte de los atletas Parapanamericanos. Nota: recordemos que $1 / 3$ de los departamentos en venta son $100 \%$ inclusivos, por lo que de esta forma podemos también llegar a las personas con discapacidad).

Gladys Tejeda es la atleta que más presencia en redes; mientras Carlos Felipa es un exmilitar del Ejército Peruano, y es muy querido y respetado por la institución (perdió la pierna en el VRAEM). El caso de María Fernanda Reyes es muy atractivo, debido a que ella vive en Villa María del Triunfo y su amor por el surf nació cuando de niña ayudaba a su madre a vender raspadillas en playas Miraflorinas, por lo que es una figura representativa para las personas del distrito (el cual es aledaño a Villa El Salvador). 


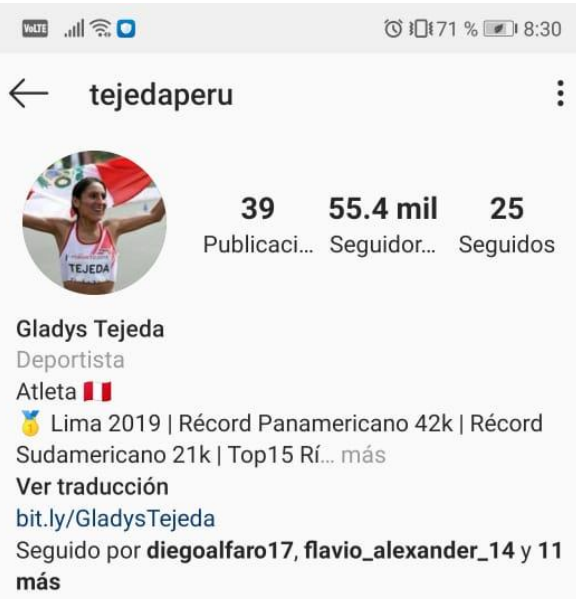

$39 \quad 55.4 \mathrm{mil} \quad 25$

Publicaci... Seguidor... Seguidos

Gladys Tejeda

Deportista

Atleta II

K Lima 2019 | Récord Panamericano 42k | Récord

Sudamericano 21k | Top15 Rí... más

Ver traducción

bit.ly/GladysTejeda

Seguido por diegoalfaro17, flavio_alexander_14 y 11 más
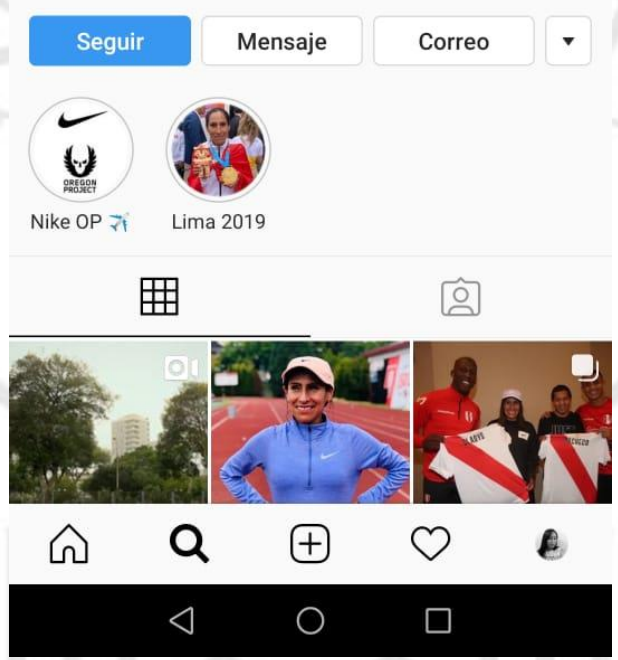

Imagen 18. Instagram Gladys Tejeda. Fuente: Instagram

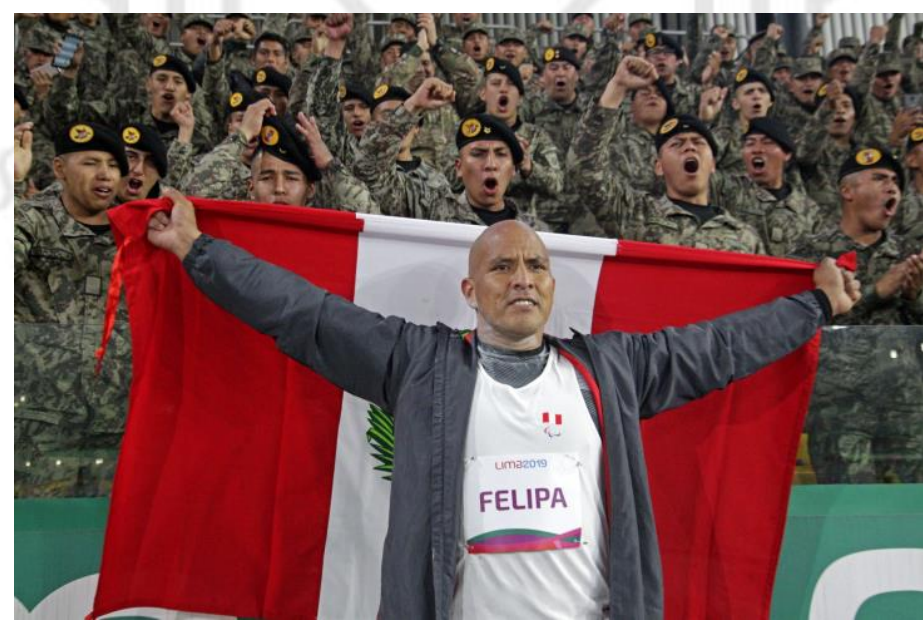

Imagen 19. Carlos Felipa. Fuente: RPP 


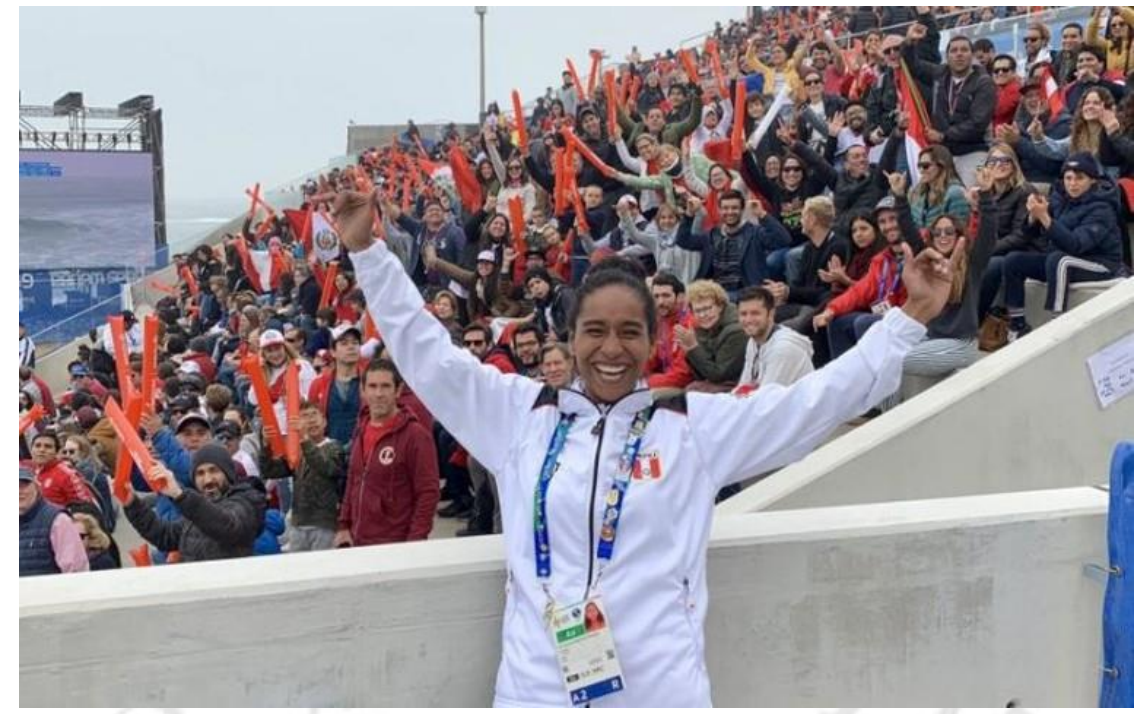

Imagen 20. María Fernanda Reyes. Fuente: Canal N

El cronograma del evento sería el siguiente (todo dentro del Condominio Villa Del Atleta):

- 9 am - 10 am: Conferencia de prensa con los atletas

- 10 am - 11 am: Catering entre miembros de presa con los atletas

- $\quad$ 12:00 - 2 pm: Entrada del público en general para recibir información sobre venta de departamentos (los atletas permanecerán para tomarse fotos y promocionar la venta)

- 2 pm - 6 pm: Ya no estarán presente los atletas, pero igualmente el público en general puede entrar para recibir información sobre venta de departamentos (incluye guía alrededor del condominio)

Nota: se hará uso de merchandising alusivo al Condominio Villa Del Atleta (lapiceros, llaveros, pelotas anti-stress), sumado al uso de volantes publicitarios y Brochure del proyecto en donde resaltaremos los bonos ofrecidos por el Fondo Mivivienda (los asesores también se encargarán de explicar todos los detalles a los posibles compradores). 


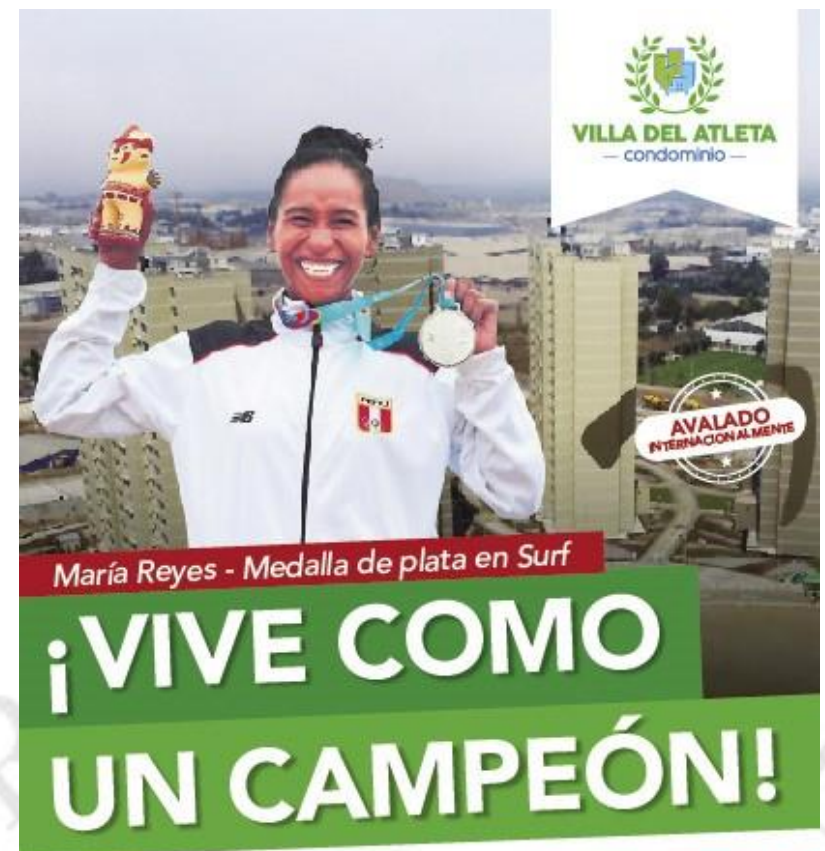

\section{Condominio ubicado en Villa EI Salvador}

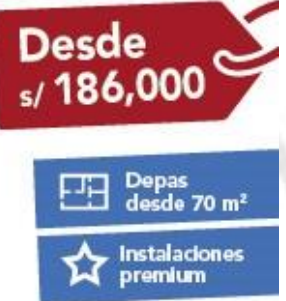

Imagen 21. Volante Villa Del Atleta - Tira. Fuente: propia 


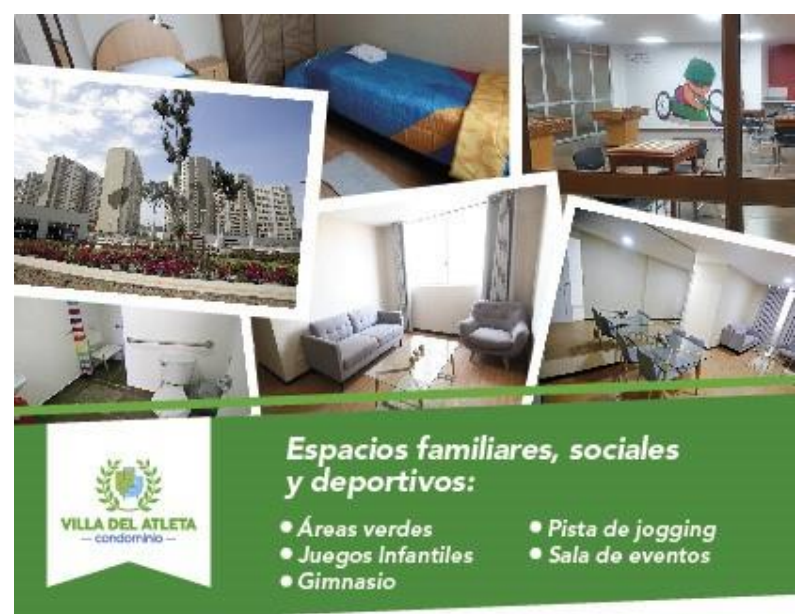

\section{Adquiérelo a través del Fondo Mivivienda:}

- Todos los departamentos cuentan con Bono Verde (4\% extra de financiamiento) - Brindamos Bono del Buen

Pagador (6\% extra de

financiamiento)

- Financiamientos hasta 20 años

- Consulta las instituciones

financieras aprobadas

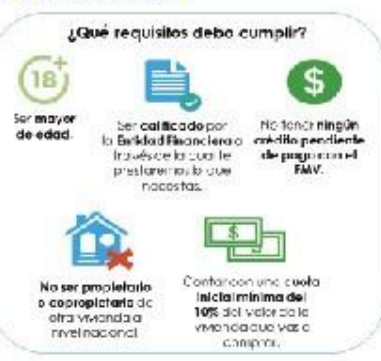

Informes: 0800-12200/villadelatleta.com

Imagen 22. Volante Villa Del Atleta - Retira. Fuente: propia

\subsubsection{Etapa de mantenimiento}

Esta etapa buscaremos mantener comunicación con una construcción de marca ya cimentada por los 3 meses de Lanzamiento.

\subsubsection{Digital}

En esta etapa nos mantendremos con presencia en Google y Facebook. Esto debido a que son medios que nos permiten cubrir el objetivo de awareness pero también contribuyen al performance. Los canales mencionados serán de suma importancia para la recolección de formularios que serán trabajados posteriormente por la fuerza de ventas. 
Las plataformas que serían usadas en esta etapa serán las siguientes:

- Google Display

- Google Search

- Youtube

Un formato especial que usaremos durante esta etapa es el *Non skippable ad: Este formato de video consta de 10 segundos y no se permite saltar. Se puede comunicar de una forma rápida los principales beneficios del producto. Usaremos esto con 3 motivos cortos, explicando los principales beneficios comerciales.

- Precio

- Áreas comunes

- Fondo MiVivienda

- Facebook

La distribución de la parrilla de contenidos de Facebook durante los 6 meses de campaña (Incluye etapa de Lanzamiento y Mantenimiento) vendría a ser la siguiente:

\begin{tabular}{|c|c|c|c|}
\hline PPV & PPA & GIF & Foto 360 \\
\hline $\begin{array}{l}\text { - Se realizarán } 3 \text { cápsulas } \\
\text { de } 15 \text { segundos que serán } \\
\text { adaptados del spot de } 30 \\
\text { segundos (Christian } \\
\text { Pacheco). El objetivo de } \\
\text { este formato es } \\
\text { comunicar el concepto } \\
\text { creativo de la campaña } \\
\text { "Vive como un Campeón" } \\
\text { - Se realizarán } 3 \text { cápsulas } \\
\text { de } 10 \text { segundos que van a } \\
\text { comunicar los atributos } \\
\text { del producto. Esto es } \\
\text { congruente con la } \\
\text { estrategia de } \\
\text { posicionamiento basada } \\
\text { en atributos. El pilar de } \\
\text { comunicación que se } \\
\text { trabajará aquí es la } \\
\text { facilidad de } \\
\text { financiamiento. } \\
\text { - En total } 6 \text { motivos }\end{array}$ & $\begin{array}{l}\text { - Este formato será } \\
\text { utilizado para comunicar } \\
\text { los } 3 \text { pilares de } \\
\text { comunicación: Proyecto, } \\
\text { facilidades de } \\
\text { financiamiento e } \\
\text { Instalaciones para } \\
\text { campeones. } \\
\text { - Serán } 72 \text { motivos }\end{array}$ & $\begin{array}{l}\text {-Este formato, por su } \\
\text { carácter lúdico y dinámico, } \\
\text { se usará para el tercer pilar } \\
\text { de comunicación : } \\
\text { Instalaciones para } \\
\text { campeones. } \\
\text { Serán } 24 \text { motivos }\end{array}$ & $\begin{array}{l}\text { - Este formato lo usaremos } \\
\text { en menor medida con } 2 \\
\text { motivos para el pilar de } \\
\text { comunicación: proyecto }\end{array}$ \\
\hline
\end{tabular}


*Priorización de lo Post Orgánico vs Pagado:

Estamos priorizando los formatos PPL, ya que uno de nuestros objetivos principales es generar tráfico a la web. Así, los formatos que irían de forma orgánica serían aquellos que son de Branding o Awareness. La distribución sería de esta manera:

\begin{tabular}{|l|l|l|}
\hline Formato & Orgánico & Pagado \\
\hline PPA & 36 & 36 \\
\hline GIF & 10 & 14 \\
\hline PPV & & 6 \\
\hline Foto 360 & & 2 \\
\hline
\end{tabular}

La elección de los PPA serán en base a su performance orgánico, ya que estos son los que tienden a tener un mejor CPM.

\subsubsection{2 $\mathrm{OOH}$}

Hemos decidido que por el alcance que tendrán en los 4 puntos establecidos previamente, los conservaremos hasta el final del segundo trimestre. Consideramos que serán un punto determinante en la venta de los departamentos del Condominio. 


\section{DISTRIBUCIÓN DE LA INVERSIÓN DE CAMPAÑA Y JUSTIFICACIÓN}

\section{Lanzamiento}

La distribución sería la siguiente:

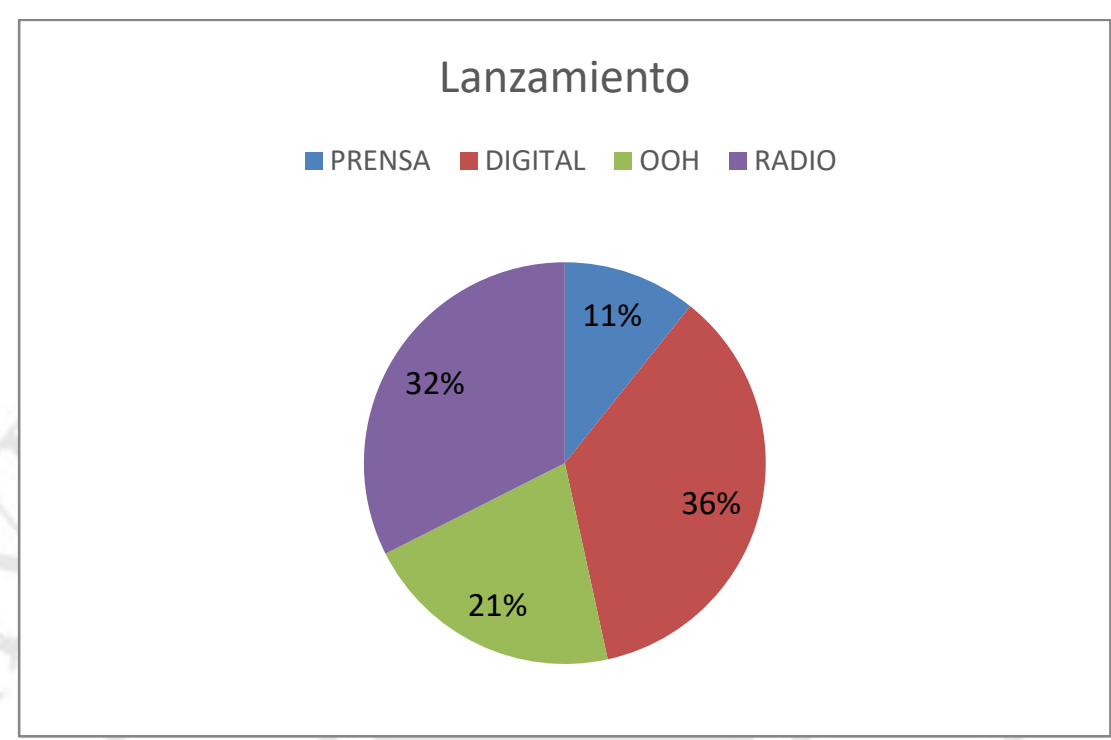

Figura 16. Distribución Campaña de Lanzamiento. Fuente: Propia

Como vemos, la mayor parte en estos primeros meses está concentrada en Radio y Digital. Tenemos una fuerte inversión en digital, debido a que logra un buen alcance a menor costo; a su flexibilidad del uso del presupuesto; y también por la capacidad de segmentación. Como segundo medio importante, tenemos a la radio con una frecuencia de 8 avisos rotativos de 20" de Lunes a Viernes. Este medio nos permite lograr la frecuencia necesaria para el buzz publicitario a un mejor costo, a comparación de otros medios ATL. Finalmente tenemos $\mathrm{OOH}$ en puntos estratégicos y prensa zonal.

\section{Mantenimiento}

Se propuso unos 3 meses de mantenimiento porque queremos mantener activa la presencia de marca hasta lograr el objetivo comercial. Por una optimización de costos nos hemos solo mantenido en $\mathrm{OOH}$ y Digital. Además, ya habríamos logrado el awareness y branding necesario con el mix de medios y el evento de lanzamiento dentro de los 3 primeros meses, por lo cual solo necesitamos mantenernos en la mente de nuestro público objetivo. La distribución sería la siguiente: 


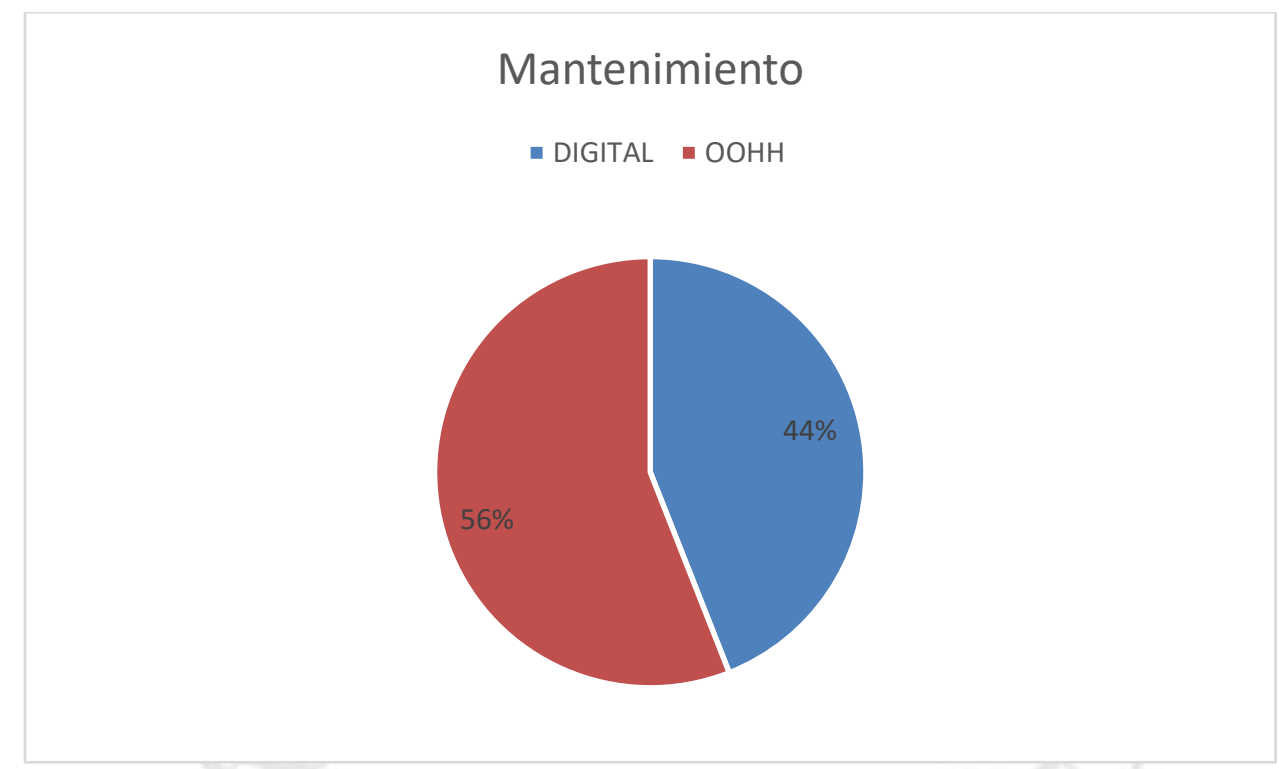

Figura 17. Distribución Campaña de Mantenimiento. Fuente: Propia

En la etapa de mantenimiento, el $\mathrm{OOH}$ tiene el mayor presupuesto (56\%), porque es un medio que construye branding de un modo más geolocalizado. Estamos manteniendo los mismos puntos estratégicos y se está incluyendo en el costo una segunda producción (Cambio de lona) para estos meses finales con el objetivo de que los paneles no se mimeticen con el entorno y sigan generando impacto.

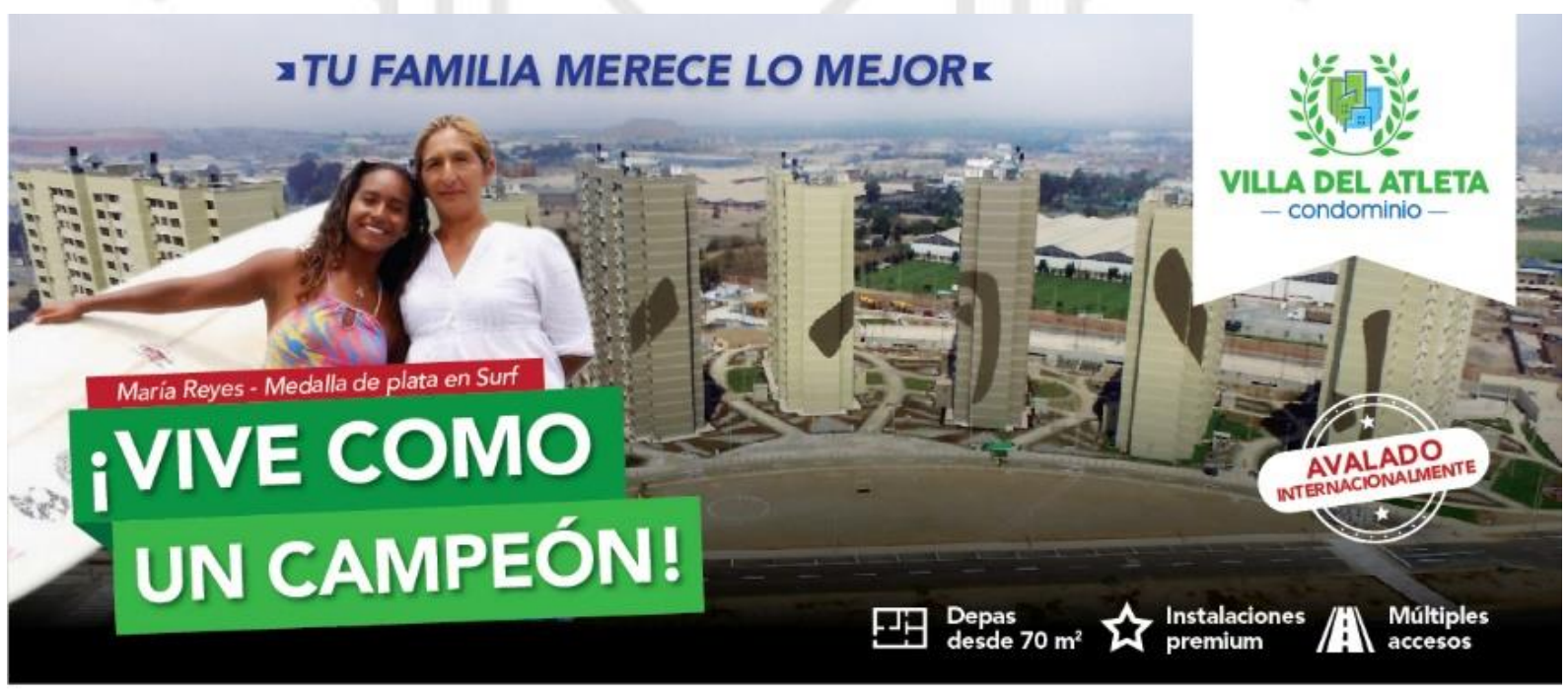

\section{Informes: 0800-12200 / villadelatleta.com}

Imagen 23. Elemento de $\mathrm{OOH}$ (Etapa Mantenimiento). Fuente: propia 
Además, seguiremos activos en Digital debido al bajo costo, su mejor alcance y porque nos estamos valiendo de formatos que nos ayudan al performance. Es decir, estos 3 meses estarían dirigidos a generar la mayor cantidad de leads o prospectos potenciales que serían trabajados por una fuerza de ventas para lograr las ventas necesarias.

Para poder medir la efectividad de ambos medios, nos basaremos en lo siguiente:

- En el caso de Digital, la mediremos en base a la cantidad de Leads conseguidos. En total estamos proyectando 4060 leads, que son importantes para el objetivo comercial.

- En el caso de $\mathrm{OOH}$, es un poco más complicado medir su efectividad en términos numéricos, debido a que no hay variables medibles que nos den a conocer el impacto real generado al público. Es por ello que sólo podríamos medirlos por la cantidad de personas que estén interesadas en adquirir un departamento, pero que no estén dentro de nuestra base de datos de la fuente digital (Leads). Es importante acotar que es una medida bastante referencial

Nuestro presupuesto en medios entre los 6 meses finales sería el siguiente:

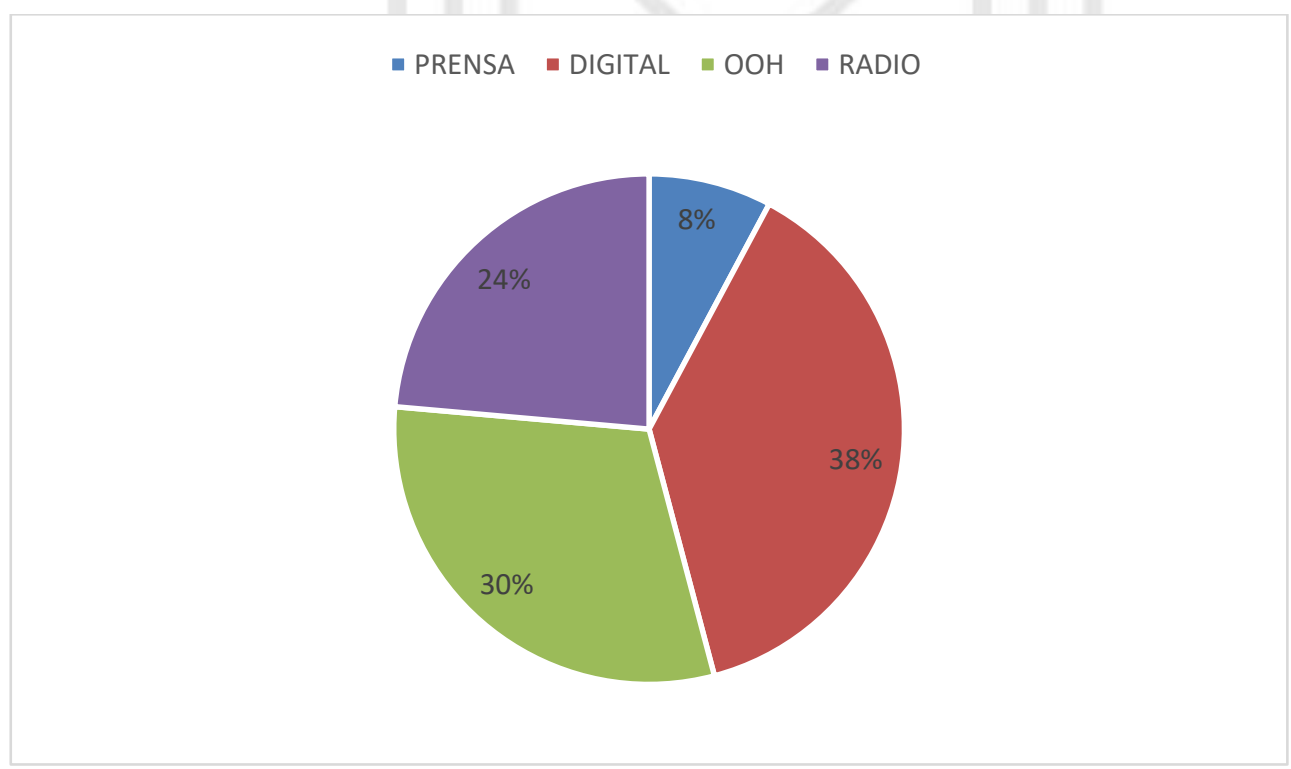

Figura 18. Distribución campaña total en los 6 meses. Fuente: Propia 


\section{CONCLUSIONES}

- El Condominio Villa del Atleta es una edificación de primer nivel que está ingresando al mercado con un precio bastante accesible a los clientes finales.

- A pesar de contar con instalaciones modernas, de fácil accesibilidad y a un precio menor para todo lo descrito, la ubicación del mismo (Villa El Salvador) limita nuestro foco de posibles compradores a personas que vivan dentro del mismo distrito o distritos aledaños. Es por ello que nuestra campaña de comunicación ha incluido un mix de medios más geolocalizado a estas zonas.

- A pesar de contar con departamentos construidos para personas con discapacidad, este segmento es bastante reducido por lo cual no ha sido elegido como el público objetivo principal del plan de comunicación.

- Los clientes potenciales del rubro inmobiliario no toman en importancia que los departamentos estén construidos para personas con discapacidad, a pesar de que implique una limitación de espacio. Así, este punto no genera una desventaja en el proceso de venta.

- Los departamentos sólo podrán ser vendidos a través del Nuevo Crédito Mivivienda, lo cual es una ventaja desde el punto del marco legal, ya que se encuentra supervisado por la Superintendencia de Banca Seguros y AFP; y por la Comisión Nacional Supervisora de Empresas y Valores del Perú. Esto genera confianza en el posible comprador.

- Se optimizó de la mejor forma el presupuesto optando por medios que impacten directamente al público objetivo en la zona de afluencia dado que nuestro producto no es masivo.

\section{RECOMENDACIONES}

- Dado que el proyecto se construyó bajo una coyuntura relevante, es recomendable que se use como recurso las relaciones públicas a lo largo del tiempo. Esto ayudará a optimizar mejor el plan de comunicación y lograr una mejor cobertura.

- Como una recomendación comercial, es importante tomar en consideración el manejo de la administración del condominio. Esto puede evitar problemas de post venta; es decir, que las personas que adquieran los departamentos los primeros meses puedan estar satisfechos y no le generen una mala reputación al condominio. Se sabe que las quejas y mala reputación impactan en la venta de los otros departamentos. 


\section{BIBLIOGRAFÍA}

ABRIL . (25 de Febrero de 2019). Abril Grupo Inmobiliario. Obtenido de ¿Cuál es el panorama del sector inmobiliario latinoamericano?: http://abril.pe/noticia/ofertainmobiliaria-

latinoamerica/?fbclid=IwAR2z3_8Mm3Y3IDqVj5cCEHVnQJiDaikaQC3LMpE iXUoMk0ZH9kkiYjljD64

America TV. (17 de Mayo de 2018). America tv. Obtenido de Internet en Perú: el 67\% de la población de Lima tiene acceso a la red: https://www.americatv.com.pe/noticias/actualidad/internet-peru-67-poblacionlima-tiene-acceso-red-n322386?fbclid=IwAR0PgiXAyLmamwqQNkEEMT5I0a5mWYx_VR885hCPz_ljVN9CRe0nUHBW88

America TV. (1 de Setiembre de 2019). America TV. Obtenido de Perú sumó 15 preseas en los Parapanamericanos y así terminó el medallero:

https://www.americatv.com.pe/deportes/polideportivo/lima-2019-peru-sumo-15preseas-parapanamericanos-y-asi-termino-medallero-n386308

Barletta, F., Pereira, M., Robert, V., \& Yoguel, G. (2013). Argentina: dinámica reciente del sector de software y servicios informáticos. Revista de la CEPAL(110), 137155. Obtenido de http://www.cepal.org/publicaciones/xml/1/50511/RVE110Yoqueletal.pdf

BolsaInmobiliaria.pe. (s.f.). BolsaInmobiliaria.pe. Obtenido de Casa o departamento, ¿cuál te conviene comprar?: https://bolsainmobiliaria.pe/blog/casa-odepartamento-cual-te-convienecomprar?fbclid=IwAR1AcCCi427moSecCfXUrQFtkFbR7dgmTIo4NEs YkzyJ N9FFl2geW6F3EZ8

Choy, M., \& Chang, G. (2014). Medidas macroprudenciales aplicadas en el Perú. Lima: Banco Central de Reserva del Perú. Obtenido de http://www.bcrp.gob.pe/docs/Publicaciones/Documentos-deTrabajo/2014/documento-de-trabajo-07-2014.pdf

CPI. (Mayo de 2019). C.P.I. AUDIENCIA RADIA DE EMISORAS (FM/AM). . Lima, Lima, Perú.

El Comercio. (4 de Setiembre de 2017). El Comercio. Obtenido de Lima 2019: consorcio Besco-Besalco gana ejecución de Villa Panamericana: https://elcomercio.pe/lima/sucesos/lima-2019-consorcio-besco-besalco-ganaejecucion-villa-panamericana-noticia-455500

El Comercio. (2 de Setiembre de 2019). El Comercio. Obtenido de El medallero completo de los Parapanamericanos Lima 2019: https://elcomercio.pe/panamericanos-lima-2019/medallero-parapanamericanoslima-2019-tabla-juegos-vivo-ver-gratis-tv-streaming-live-directo-noticia-670966

El Comercio. (12 de Agosto de 2019). El Comercio. Obtenido de Lima 2019: Estos son todos los medallistas peruanos que recibirán un departamento: https://elcomercio.pe/panamericanos-lima-2019/noticias/lima-2019-sonmedallistas-peruanos-recibiran-departamento-noticia-nndc-664034

El Comercio. (2 de Setiembre de 2019). El Comercio. Obtenido de Parapanamericanos 2019: los medallistas peruanos que recibirán un departamento | FOTOS: https://elcomercio.pe/panamericanos-lima-2019/parapanamericanos-2019medallistas-peruanos-recibiran-departamento-fotos-noticia-nczd-671127 
EL COMERCIO. (28 de Marzo de 2019). EL COMERCIO. Obtenido de ¿Cómo utilizan las redes sociales los peruanos?: https://elcomercio.pe/tecnologia/redessociales/facebook-utilizan-redes-sociales-peruanos-noticia-620588

El Peruano. (21 de Agosto de 2018). El Peruano. Obtenido de https://elperuano.pe/noticia-toda-compra-casas-y-autos-sera-bancarizada70332.aspx

Expreso. (21 de Julio de 2019). Expreso. Obtenido de Estado desembolsó 4200 millones de soles por los Juegos Panamericanos: https://www.expreso.com.pe/actualidad/estado-desembolso-4200-millones-desoles-por-los-juegos-panamericanos/

García Nieto, J. P. (2013). Consturye tu Web comercial: de la idea al negocio. Madrid: RA-MA.

GESTIÓN. (7 de Setiembre de 2017). Inmobiliaria. Obtenido de Desarrolladora: ¿Casas o departamentos, cuál se vende más en el sector inmobiliario?: https://gestion.pe/tu-dinero/inmobiliarias/desarrolladora-casas-departamentosvende-sector-inmobiliario-143103noticia/?fbclid=IwAR3ghWkqkVgz7BmSONyQ6TrnG9Hy8VVgiqpe5yNgFuO beyr6lrPhlxaFzo

GESTIÓN. (28 de Agosto de 2019). GESTIÓN. Obtenido de Villa Panamericana: Valor de departamentos sería muy caro para la zona: https://gestion.pe/economia/villapanamericana-valor-de-departamentos-seria-muy-caro-para-la-zona-noticia/

GESTIÓN. (19 de Agosto de 2019). GESTIÓN. Obtenido de Precio del metro cuadrado en Lima crecería hasta en $8 \%$ al cierre de 2019:

https://gestion.pe/economia/precio-del-metro-cuadrado-en-lima-creceria-hastaen-8-al-cierre-de-2019-noticia/

GFK. (24 de Abril de 2017). GFK Growth from Knowledge. Obtenido de Informe de Internet 2017 - Digital Marketing Toolkit Peru: https://www.gfk.com/espe/insights/press-release/informe-de-internet-digital-marketing-toolkit-peru/

INEI. (Marzo de 2015). INEI. Obtenido de Perú - Características de la Población con Discapacidad:

https://www.inei.gob.pe/media/MenuRecursivo/publicaciones_digitales/Est/Lib 1209/Libro.pdf

INEI. (Marzo de 2015). INEI. Obtenido de Perú - Características de la Población con

Discapacidad:

https://www.inei.gob.pe/media/MenuRecursivo/publicaciones_digitales/Est/Lib 1209/Libro.pdf

INEI. (18 de Enero de 2018). INEI. Obtenido de Lima alberga 9 millones 320 mil habitantes al 2018: https://www.inei.gob.pe/prensa/noticias/lima-alberga-9millones-320-mil-habitantes-al-2018-10521/

INEI. (Octubre de 2018). INEI. Obtenido de RESULTADOS DEFINITIVOS DE LOS CENSOS NACIONALES 2017:

https://www.inei.gob.pe/media/MenuRecursivo/publicaciones_digitales/Est/Lib $1583 /$

IPSOS. (2018). IPSOS. Obtenido de Perfil del adulto joven peruano: https://marketingdata.ipsos.pe/user/miestudio/2413

IPSOS. (2019). IPSOS. Obtenido de Gen X: Perfil del adulto: https://marketingdata.ipsos.pe/user/miestudio/2536

Ministerio de Economía y Finanzas. (25 de Abril de 2019). Informe de Actualización de Proyecciones Macroeconómicas 2019-2022. Obtenido de Informe de Actualización de Proyecciones Macroeconómicas 2019-2022 : 
https://www.mef.gob.pe/contenidos/pol_econ/marco_macro/IAPM_2019_2022. pdf

Panamericana. (Julio de 2019). Panamericana. Obtenido de Carlos Neuhaus, el artífice de los Juegos Panamericanos Lima 2019:

https://panamericana.pe/locales/271222-carlos-neuahus-artifice-juegospanamericanos-lima-2019

Properati . (12 de Junio de 2019). Properati. Obtenido de Reporte del Mercado Inmobiliario - Lima Junio 2019: https://blog.properati.com.pe/reporte-delmercado-inmobiliario-lima-junio2019/?gclid=EAIaIQobChMIIYi5mrO45AIVBpyzCh0M6QS7EAAYASAAEgJ jvfD_BwE

Reader Data. (17 de Setiembre de 2019). Afinidad de lectoría HM 20-34 CDE-Lima, HM 35-54 CDE. Lima, Lima, Perú.

RPP. (4 de Diciembre de 2018). RPP. Obtenido de ¿Qué significa ser una persona con discapacidad en el Perú?: https://vital.rpp.pe/salud/que-significa-ser-unapersona-con-discapacidad-en-el-peru-noticia-1167146

telesur. (11 de Agosto de 2019). telesur. Obtenido de Terminan los Panamericanos y así queda el medallero Lima 2019: https://www.telesurtv.net/news/medallerojuegos-panamericanos-lima-20190811-0059.html

TGI. (2019). Afinidad de medios HYM Lima 25 a 35 CDE. Lima, Lima, Perú.

TGI. (2019). Afinidad de medios HYM Lima 35 a 55 CDE. Lima, Lima, Perú.

UNAYTA. (18 de Diciembre de 2018). UNAYTA. Obtenido de Teoría del color: Guía básica del color : https://unayta.es/teoria-del-color/

Wittmann, R. (2006). ¿Hubo una revolución en la lectura a finales del siglo XVIII? En G. Cavallo, \& R. Chartier, Historia de la lectura en el mundo occidental (págs. 435-472). México D.F.: Santillana.

ZETAFONTS. (s.f.). ZETAFONTS. Obtenido de COCOGOOSE: https://www.zetafonts.com/cocogoose

\section{ANEXOS}

Los anexos se han adjuntado en el link del repositorio digital mencionado en las primeras páginas. 